\title{
Fuel
}

\section{Effects of natural micro-fracture morphology, temperature and pressure on fluid flow in coals through fractal theory combined with lattice Boltzmann method --Manuscript Draft--}

\begin{tabular}{|c|c|}
\hline Manuscript Number: & JFUE-D-20-04146R1 \\
\hline Keywords: & $\begin{array}{l}\text { Coal; Micro-fractures morphology; Permeability; Fractal theory; Lattice Boltzmann } \\
\text { method }\end{array}$ \\
\hline Corresponding Author: & $\begin{array}{l}\text { Yidong Cai, Ph.D } \\
\text { China University of Geosciences, Beijing } \\
\text { Beijing, CHINA }\end{array}$ \\
\hline First Author: & Qian Li \\
\hline \multirow[t]{4}{*}{ Order of Authors: } & Qian Li \\
\hline & Dameng Liu \\
\hline & Yidong Cai, Ph.D \\
\hline & Yingfang Zhou \\
\hline Abstract: & $\begin{array}{l}\text { The fluid flow behaviors during the production of coalbed methane (CBM) are generally } \\
\text { restricted by the pre-existing natural fractures in coal seams. To better understand the } \\
\text { effect of natural micro-fracture morphology on the flow capacity, nine coals collected } \\
\text { from Ordos Basin were subjected to optical microscope observations to obtain micro- } \\
\text { fractures morphology. And then, an improved box-counting method (BCM) was used to } \\
\text { quantify the complexity of the micro-fracture network planar distribution. Besides, the } \\
\text { lattice Boltzmann method (LBM) was adopted to simulate the flow in the complex } \\
\text { micro-fracture network under different pressures and temperatures. Finally, factors } \\
\text { affecting the flow capacity in micro-fracture were elaborated. The results show that the } \\
\text { micro-fractures generally present dendritic, reticular, filamentous and orthogonal } \\
\text { structures. The natural micro-fracture morphology has a remarkable impact on flow } \\
\text { behavior, in which the presence of dominant channels with a length of } \sim 498.26 \mu \text { m } \\
\text { and a width of } \sim 10.96 \mu \text { m has a significant contribution to permeability, while the } \\
\text { orthogonal micro-fracture network normally is not conducive to fluid flow. The fractal } \\
\text { dimension extracted from the nine coals varies from } 1.321-1.584 \text {, and the permeability } \\
\text { calculated from LBM method varies from } 0.147 \text { to } 0.345 \text { D; in contrast to other studies, } \\
\text { a non-monotonic change, an inverted U-shaped, of permeability on fractal dimension } \\
\text { was observed. Moreover, permeability decreases as pressure increases and increases } \\
\text { with increasing temperature due to the physical properties of methane and coal matrix. } \\
\text { Therefore this work may contribute to understand the process of hydrofracturing and } \\
\text { hydrothermal methods for improving CBM reservoirs during enhancing CBM recovery. }\end{array}$ \\
\hline
\end{tabular}




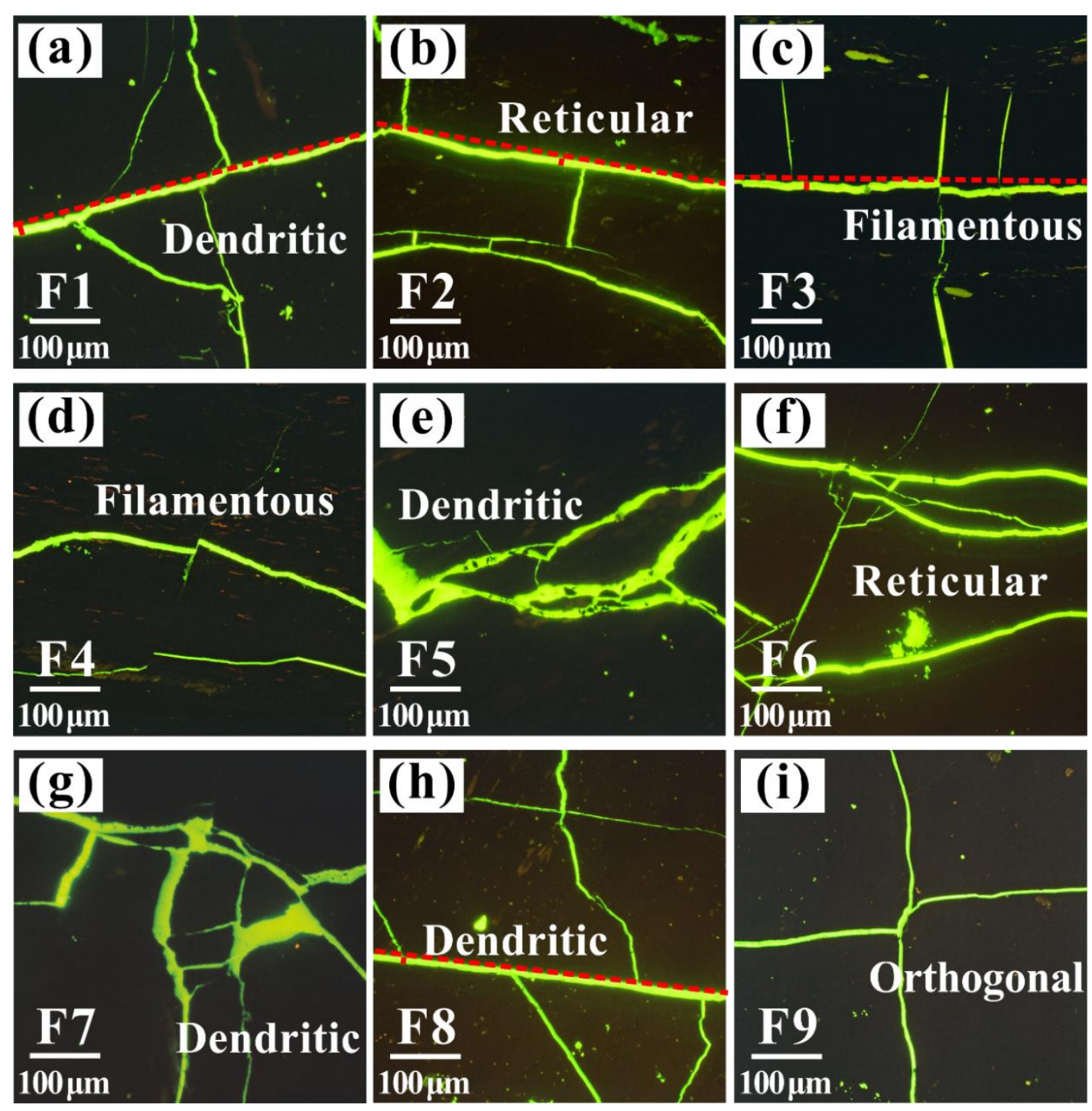


[30] Yao YB, Liu DM. Microscopic characteristics of microfractures in coals: an investigation into permeability of coal. Procedia Earth and Planetary Science 2009;1(1):903-10.

[35] Li Q, Liu DM, Cai YD, Zhao B, Qiu YK, Zhou YF. Scale-span pore structure heterogeneity of high volatile bituminous coal and anthracite by FIB-SEM and X-ray $\mu$-CT. J Nat Gas Sci Eng 2020;81:103443. 
to a decrease in permeability.

15. Language should be polished.

Response: Thank you very much for your comment. We have polished the language, sorted out the logic and supplement details.

\section{Reference:}

[1] Li Q, Liu DM, Cai YD, Zhao B, Qiu YK, Zhou YF. Scale-span pore structure heterogeneity of high volatile bituminous coal and anthracite by FIB-SEM and X-ray $\mu$-CT. J Nat Gas Sci Eng 2020;81:103443

[2] Otsu N. A Threshold Selection Method from Gray-Level Histograms. IEEE Transactions on Systems, Man, and Cybernetics 1979;9(1):62-6.

[3] Prakongkep N, Suddhiprakarn A, Kheoruenromne I, Gilkes RJ. SEM image analysis for characterization of sand grains in Thai paddy soils. Geoderma 2010;156(1-2):20-31.

[4] Zhou HW, Xie H. Direct estimation of the fractal dimensions of a fracture surface of rock. Surf Rev Lett 2003;10(5):751-62.

[5] Liu SM, Li XL, Wang DK, Wu MY, Yin GZ, Li MH. Mechanical and acoustic emission characteristics of coal at temperature impact. Natural Resources Research 2020;29(3):1755-72.

[6] Yao J, Zhao JL, Zhang M, Zhang L, Yang YF, Sun ZX, et al. Microscale shale gas flow simulation based on Lattice Boltzmann method. Acta Petrolei Sinica 2015;36(10):1280-9.

[7] Pan JN, Hou QL, Ju YW, Bai HL, Zhao YQ. Coalbed methane sorption related to coal deformation structures at different temperatures and pressures. Fuel 2012;102:760-5.

[8] Cai YD, Pan ZJ, Liu DM, Zheng GQ, Tang SH, Connell LD, et al. Effects of pressure and temperature on gas diffusion and flow for primary and enhanced coalbed methane recovery. Energ Explor Exploit 2014;32(4):601-19.

[9] Tao CQ, Wang YB, Li Y, Ni XM, Gao XD. Adsorption mechanism and kinetic characterization of bituminous coal under high temperatures and pressures in the Linxing-Shenfu area. Acta Geol Sin-Engl 2020;94(2):399-408.

[10] Liu CJ, Sang SX, Zhang K, Song F, Wang HW, Fan XF. Effects of temperature and pressure on pore morphology of different rank coals: Implications for $\mathrm{CO} 2$ geological storage. Journal of CO2 Utilization 2019;34:343-52.

[11] Wang JJ, Kang QJ, Chen L, Rahman SS. Pore-scale lattice Boltzmann simulation of microgaseous flow considering surface diffusion effect. Int J Coal Geol 2017;169:62-73.

[16] Liu XF, Nie BS. Fractal characteristics of coal samples utilizing image analysis and gas adsorption. Fuel 2016;182:314-22.

[32] Zhou HW, Xie H. Direct estimation of the fractal dimensions of a fracture surface of rock. Surf Rev Lett 2003;10(5):751-62.

[36] Wu H, Zhou YF, Yao YB, Wu KJ. Imaged based fractal characterization of micro-fracture structure in coal. Fuel 2019;239:53-62. 


\section{Highlights}

$>$ Dominant channels in the natural micro-fractures greatly improve the permeability.

$>$ Flow features in micro-fractures with various morphologies are quite different.

$>$ Pressure and temperature have opposite influence on coal permeability. 
1 Effects of natural micro-fracture morphology, temperature and pressure in

2 earls on fluid flow in coals through fractal theory combined with lattice

3 Boltzmann method

4 Qian $\mathrm{Li}^{\mathrm{a}, \mathrm{b}}$, Dameng Liu ${ }^{\mathrm{a}, \mathrm{b}}$, Yidong Cai ${ }^{\mathrm{a}, \mathrm{b}^{*}}$, Bo Zhao $^{\mathrm{c}}$, Yuejian Lu ${ }^{\mathrm{a}, \mathrm{b}}$, Yingfang Zhou ${ }^{\mathrm{d}}$

$5 \quad{ }^{a}$ School of Energy Resources, China University of Geosciences, Beijing 100083, China

${ }^{b}$ Coal Reservoir Laboratory of National Engineering Research Center of CBM Development \& Utilization, China

7 University of Geosciences, Beijing 100083, China

${ }^{c}$ School of Water Resources and Environment, China University of Geosciences, Beijing 100083, China

${ }^{d}$ School of Engineering, Fraser Noble Building, King's College, University of Aberdeen, AB24 3 UE Aberdeen, UK

10 Abstract

11 The fluid flow behaviors during the production of coalbed methane (CBM) are generally

12 restricted by the pre-existing natural fractures in coal seams. To better understand the effect of

13 natural micro-fracture morphology on the flow expacitycapability, nine coals collected from

14 Ordos Basin were subjected to optical microscope observations to obtain micro-fractures morphology. And then, an improved box-counting method (BCM) was used to quantify the

16 complexity of the micro-fracture network planar distribution. Besides, the lattice Boltzmann

17 method (LBM) was adopted to simulate the flow in the complex micro-fracture network under

18 different pressures and temperatures. Finally, factors affecting the flow eapacity capability in

19 micro-fracture were elaborated. The results show that the micro-fractures generally present

20 dendritic, reticular, filamentous and orthogonal structures. The natural micro-fracture

21 morphology has a remarkable impact on flow behavior, in which the presence of dominant

| $\quad$ "Corresponding author, Email address: yidong.cai@ @ugb.edu.cn (Y. Cai) 

flow. The fractal dimension extracted from the nine coals varies from 1.321-1.584, and the permeability calculated from LBM method varies from 0.147 to $0.345 \mathrm{D}$; in contrast to other studies, a non-monotonic change, an inverted U-shaped, of permeability on fractal dimension was observed. Moreover, permeability decreases as pressure increases and increases with increasing temperature due to the physical properties of methane and coal matrix.

29 TherefereTherefore, this work may contribute to understanding the process of hydrofracturing

30 and hydrothermal methods for improving CBM reservoirs during enhancing CBM recovery.

31 Keywords: Coal; Micro-fractures morphology; Permeability; Fractal theory; Lattice

32 Boltzmann method

\section{1. Introduction}

35 Coalbed methane (CBM) is an essential component in of the unconventional energy system due

36 to its huge reserves, the reservoir of which is deemed as a dual-porous medium with pores in

37 matrix and fractures/cleats [1-3]. Pores are generally associated with the processes of gas storage, desorption and diffusion [4]. For fractures, composed by micro-fractures and macrofractures, they are the most important physical attribute governing gas flow in a CBM reservoir

$40[5,6]$. Generally speaking, natural fractures primarily contributed to the permeability of coal,

41 while the pores in coal matrix haves very limited influence on coal permeability [7].Numerous

42 Extensive works including experiments and numerical simulations have been conducted to 43 understand the performance of micro-fracture with the width at the-micron scale due to its 
importance on CBM production [6ㅇ-2524]. The above works on coal fractures/cleats can be classified into two groups: characterization of micro-fracture networks and the exploration of gas flow behavior.

Multiple experimental methods can be used to characterize micro-fractures performanceproperties (e.g. , including Lowlow-field nuclear magnetic resonance (NMR) [8, 9], X-ray computed micro-tomography (X-ray $\mu \mathrm{CT}$ ) [10-12], focused ion beam coupled with scanning electron microscopy (FIB-SEM) and the classic optical microscopy [13]. NMR is a non-destructive measurement and it has been adopted successfully to detect and quantify the pore-fracture structure of coals [8], where the $T_{2}$ spectrum is-larger than $100 \mathrm{~ms}$ represents micro-fracture [9]. However, the detailed morphological features of micro-fracture are not accessible through NMR. For-X-ray $\mu \mathrm{CT}$, it can provide realistic three-dimensional digital images and different components reconstruction [10-12]. For instances, Roslin et al. proposed an effective method to overcome the partial volume effect of low resolution images based on micro-CT technique. And-Jenkins et al. [12] utilized X-ray $\mu \mathrm{CT}$ to dynamically measure the deformation behavior of tested rock under various loading conditions. Zhou et al. [15] used FIB SEM to visualize the geometric structure of pere fracture space, and evaluated the seepage eapacity of coal samples based on the established three-dimensional pore network model. However, X-ray $\mu \mathrm{CT}$ and FIB SEM areis expensive and not ecenomically suitable, and are time-consuming. Compared with the above techniques, the micro-fracture morphology observation by optical microscopy is not only economically suitableinexpensive but also easy to obtain clear morphologies miero fractures morphelogies[13]. Besides, the fractal dimension can extend the qualitative description of the micro-fracture network to a quantitative description,
Formatted: Not Highlight

Formatted: Not Highlight

Formatted: Font color: Auto 
which quantifies its complexity of distribution [14, 15]For assessment of fracture complexity,

fractal dimension is generally used to characterize the complexity of pore-fracture structure in nattral geological materials, e.g., shales and coals. The box-counting method (BCM) is one of the most popular algorithms $[16,17]$ to acquire the complexity, namely fractal dimension, through the images of pore-fracture structure. Herein, the BCM will be utilized to quantify the complexity of micro-fractures.

Besides fractal theory, dOn the other hand, direct numerical methods including finite difference method (FDM) [18], finite element method (FEM) [19] and finite volume method (FVM) [20] can be effectively adopted to simulate the flow behavior in micro-fracture networks. For instance, Liu et al. [20] adopted a simulator derived from FDM to solve the multi-mechanistic gas flow model and successfully tested against two sets of in situ field data. And Sun et al. [21] used FEM to establish the semi-solid permeability of microstructure constructed from a Voronö̈ tessellation algorithm. Based on FVM and considering the transient incompressible Newtonian fluid, Almasoodi and Reza [22] simulated the permeability on the FIB SEM images of shale. The above methods (FDM, FEM, and FVM), But these traditional simulation methods on the basis of Navier-Stokes equations,__require complicated meshing process to define the simulation domain and are challenging to solve complex geometric boundaries and have low parallel efficiency [18-20]. The lattice Boltzmann method (LBM), as a typical mesoscopic method, has a strong advantage in simulating the flow behavior of porous media with irregular boundaries [21, 22]. For example, Wang et al. [23] decomposed the three-dimensional fracture geometry into primary and secondary roughness through wavelet analysis, and investigated the role of the latter in the flow of rock fractures using LBM. And Zhao et al. [24] adopted LBM

\section{Formatted: Font color: Auto}

Formatted: Font color: Auto

Formatted: Font color: Auto 
to investigate-discuss the effect of structure, surface roughness and aperture on flow in

89 constructed fracture networks with rough surfaces. Generally speaking, natural fractures

90

91

92

93

94

95

96 primary contributed to the permeability of coal, while the coal matrix has very limited influence

en ceal permeability [7].

The previous works on coal fractures/cleats can be classified into two parts: characterization of micro-fracture networks $[68-1314]$ and the exploration of gas flow behavior in the microfracture networks [185-234]. IHence, it is ef significant for understanding the effect of natural fracture network on permeability - value tothrough investigatinge the characteristics and distribution of natural fractures in coal-to understand its permeability. Besides, owing to the complexity of the natural fracture network in coal, much related work has performed flow simulation in the fracture network constructed by algorithms such as Voronoi tessellations method [24, 25] and Fracture Pipe Network Model (FPNM) [26], whereas rare researches have been conducted on the real complex natural fracture networks with specific morphologies. Many studies adopted an idealistic tube model with a circular cross-section to simplify the flow simulation $[27,28]$. But $\underline{\text { However, in most cases, the shape of micro-fractures is non-circular }}$ and irregular in coal, which is much complicated, non-cireular and irregular. Therefore, Yuan et al. [29] compared the original-realistic shape with the permeability characteristics of circle, square and equilateral triangular cross-sections. And it was, which found that the permeability of the network with circle cross-section is the highest, followed by the eriginal-realistic shape, and the final are square and equilateral triangular, which. This finding corroborates the importance of accurately acquiring morphological features in micro-fracture networks. (morphological features). Besides, owing to the complexity of the natural fracture network in
Formatted: Not Highlight

Formatted: Font color: Auto 
Network Model (FPNM) [28], whereas but rare researches have been conducted on the reat

eharacteristic with real morphologies of miero fractmres.

In this study, we aim to investigate the flow behavior in natural micro-fractures with various morphologies under different pressures and temperatures. To detailed address the flow behavior in micro-fractures, the specific morphologies of natural micro-fractures were firstly obtained by optical microscopy. And then, the BCM was used to quantify the complexity of the natural micro-fracture network. Finally, the LBM was applied to simulate the flow behavior in the natural micro-fracture network with specific morphologies in coals, and the dominating controlling factors were discussedrevealed. This study may provide insights into the flow mechanisms of natural micro-fracture networks with complex morphologies $y$ in unconventional reservoirs.

2. Methodology and validation

\subsection{Coal sampling and basic analysesanalysis}

126 Nine coal blocks $\left(30 \times 30 \times 30 \mathrm{~cm}^{3}\right)$ with different coal ranks were selected from the Eeastern Ordos Basin, north China. The maximum vitrinite reflectance $\left(\mathrm{R}_{\mathrm{o}, \max }\right)$ and maceral composition were carried out with a Leitz MPV-III microscope photometer following the Chinese National Standard of GB/T 6948-1998. The $\mathrm{R}_{\mathrm{o}, \max }$ varies from $0.62 \%$ to $1.78 \%$ as shown in Table 1 , which may indicate the variable inner micro-fractures existed [30]. Coal macerals were tested 131 by the point counting technique according to the scheme of the International Committee effor 
132 Coal and Organic Petrology [31]. The coal composition differs, with vitrinite of 65.4-90.2\%,

133 inertinite of $4.5-25.6 \%$, exinite of $0-5.9 \%$ and mineral being $0.2-8.3 \%$. Natural mMicro-

134 fractures of coals are-selectively developed in macerals/submacerals, for example, micro-

135 fractures is are most developed well in the submacerals of telocollinites while others including

136 the desmocollinite, vitrodetrinite, inertodetrinite and semifusinite are not conducive to micro-

137 fractures developmented [30].

\section{$138 \quad 2.2$ Micro-fractures characterization by optical microscopy}

139 The morphological characteristics of the natural micro-fractures can be clearly observed by

140 optical microscopy. The specific preparation process of used samplecoals-preparation is as

follows: first melteda certain proportion of resin and paraffin was melted, and then was poured

it into the micro-fractures of coal. After that, the coal-blocks were cut and polished into the

sampleblocks with the area of $\sim 3 \times 3 \mathrm{~cm}^{2}$. To the end, LABORLUX 12 POL optical microscopy

of the polished sample obinincluding the morphological characteristics. The coal samples

were polished into slices with an area of $3 \mathrm{~cm} \times 3 \mathrm{~cm}$ first. Then observation of the micro-

fractures was performed using LABORLUX 12 POL optical microscopy (Leitz Company of

Germany) at China University of Geosciences at Beijing (CUGB). Natural Mmicro-fractures

morphologies images with the image resolution of $0.4937 \mu \mathrm{m}$ were ebtained-achieved, which

contain as show in Fig. 1 and varied-various shapes involving dendritic, reticular, filamentous

and orthogonal structure as shown in Fig. 1 ete. It can be found that tThe natural dendritic

micro-fracture network is mostly composed of a backbone and several branches extending out 
regular type (Fig. 1b) and irregularemplicateddisorganized type (Fig. 1f)-, which have Tthe common feature is that there areof more than two main channels and the part of branches connecting the main channels, and their difference is whether the channel is curved and disorganized. The natural filamentous micro-fracture network primarily has a channel similar to a withribbon with weakweak connectivity-is mere likely to deterate of its narrowness. Comparatively, What is easier to distinguish is-the orthogonal micro-fracture network is easy to distinguish, which has a pair of orthogonal channels.-

After collecting the images, these images need to be preprocessed including noise reduction and image segmentation. First to reduce noise, which normally due to the limitations of the experimental equipment, herein the median filter is chosen to reduce the noise for studied images (Fig. 2). And then the images need to be segmented by Otsu algorithm, which has been proved to be an. Previous researchers have proved that global thresholding method is effective and conciseness threshold segmentation method to determine the threshold [16, 32] for image segmentation. After thresholding, the micro-fractures were distinguished from the background in the selected coals. As shown in Fig. 2c, black is the micro-fracture and white is the coal matrix in the binary images. Detailed observation shows that the noise in the red rectangular frame of Fig. 2c is significantly less than that in Fig. 2b; what's more the edge of the microfracture in Fig. 2c is smoother after noise reduction.

\subsection{Fractal theory applied for micro-fractures network}

The fractal theory proposed by Mandelbrot [33] can be used to evaluate the natural porous properties such as coals and shales. The fractal dimension, the characteristic parameter of fractal theory, can effectively quantify the complexity of pore-fracture structure. For a two-
Formatted: Font color: Blue

Formatted: Not Highlight

Formatted: Font color: Blue 


$$
D=-\lim _{r \rightarrow 0} \frac{\log (N(r))}{\log (r)}
$$

where $N(r)$ is the number of boxes required to cover the complete image-completely. The

side length $r$ of the box needs to be assigned a series of values, and the number of boxes $N(r)$

required to cover the image is counted. Then a set of $[\log (r), \log (\mathrm{N}(r))]$ values of each sample

are plotted in the coordinate system with the abscissa of $\log (r)$ and the ordinate of $\log (\mathrm{N}(r))$.

The slope is determined by the least square fitting method, which is the fractal dimension $D$.

191 Within the calculation process, we adopted the method proposed by $\mathrm{Wu}$ et al. [36] to avoid boundary effects, using the common divisors of the length and width of the image as a series of box sizes. in Table 1.

Formatted: Font color: Auto

\begin{tabular}{|l|}
\hline Formatted: Font: Italic \\
\hline Formatted: Font: Italic \\
\hline Formatted: Font: Italic \\
\hline Formatted: Font: Italic \\
\hline Formatted: Font: Italic \\
\hline Formatted: Font: Italic \\
\hline Formatted: Font: Italic \\
\hline Formatted: Font color: Auto \\
\hline
\end{tabular}

Formatted: Font: Italic 
198 In the present study, the flow simulation was carried out based on the Bhatnagar Gross Krook (BGK) model [37], which is the most widely used model. The distribution functions $f_{i}$ can be expressed as:

$f_{i}\left(x+\boldsymbol{e}_{i} \delta_{t}, t+\delta_{t}\right)-f_{i}(x, t)=-\frac{1}{\tau}\left[f_{i}(x, t)-f_{i}^{(e q)}(x, t)\right]$

$\boldsymbol{e}_{i}$ is the discrete propagation velocity vector in $i$ direction, $f_{i}^{(e q)}$ is the equilibrium distribution function of $\boldsymbol{e}_{i}$ for density $\rho$ and fluid velocity $\boldsymbol{u}$.

The relaxation time $\tau$ is adopted:

$$
\tau=\frac{v}{c_{s}^{2} \delta_{t}}+\frac{1}{2}
$$

where $v$ is the kinematic viscosity; $c_{s}=\sqrt{R T}=c / \sqrt{3}$ is the sound speed, in which $R$ is the gas constant and $T$ is the temperature ${ }_{\overline{9}}$.

The DnQb model ( $\mathrm{n}$ is the spatial dimension and $\mathrm{b}$ is the number of discrete velocity vectors) 210 proposed by Qian et al. [38] is the most representative. We utilize the D2Q9 model (see Fig.

$2112 \mathrm{~d})$, and its equilibrium distribution function $f_{i}^{(e q)}$ can be expressed as:

$f_{i}^{(e q)}=\omega_{i} \rho\left[1+\frac{\boldsymbol{e}_{i} \cdot \boldsymbol{u}}{c_{s}^{2}}+\frac{\left(\boldsymbol{e}_{i} \cdot \boldsymbol{u}\right)^{2}}{2 c_{s}^{4}}-\frac{\boldsymbol{u} \cdot \boldsymbol{u}}{2 c_{s}^{2}}\right]$ where $c=\delta_{x} / \delta_{t}$ is the lattice velocity, and both the lattice size $\delta_{x}$ and time step $\delta_{t}$ are set to 1 . The $\boldsymbol{e}_{i}$ and weight coefficient $\omega_{i}$ are defined as:

$$
\begin{aligned}
& \boldsymbol{e}_{i}=c\left[\begin{array}{lllllllll}
0 & 1 & 0 & -1 & 0 & 1 & -1 & -1 & 1 \\
0 & 0 & 1 & 0 & -1 & 1 & 1 & -1 & -1
\end{array}\right] \\
& i=0,1, \ldots, 8
\end{aligned}
$$


$216 \omega_{i}= \begin{cases}4 / 9 & i=0 \\ 1 / 9 & i=1-4 \\ 1 / 36 & i=5-8\end{cases}$

217 For isothermal gas flow, the macroscopic parameters, such as density and momentum, can be 218 determined as:

$\rho=\sum_{i} f_{i}, \rho \boldsymbol{u}=\sum_{i} \boldsymbol{e}_{i} f_{i}$

The pressure boundary conditions are applied to the inlet and outlet. The stationary non-slip boundary is drawn on the solid wall. We default the simulation to reach a steady state when the velocity change of each grid between two time steps is less than $0.0001 \%$. Note that the fact that the isothermal boundary condition has been adopted in the above deduction.

The lattice units are used in the above mentionedabove-mentioned parameters. Therefore, it is necessary to convert the studied physical quantity (e.g. permeability) from the lattice unit to the physical unit. The permeability can be determined by Eq. (8) following the theoretical model of capillary model.

$228 \frac{K}{K_{L B M}}=\left(\frac{L}{L_{L B M}}\right)^{2}$ where $K$ and $K_{L B M}$ are the intrinsic permeability with physical unit and the permeability simulated by LBM, respectively. $L$ is the real scale of coal sample and $L_{L B M}$ is the scale of LBM. Other physical property parameters such as kinematic viscosity required for methane under different pressure and temperature conditions can be obtained from the open source software called Peace software.

2.53. Validation of Box-counting and Lattice lattice Boltzmann methods

236 Sierpinski Carpet as a classic figure (as shown in Fig. 3a) in fractal theory can be used to verify 
the accuracy of our calculation program. The definition of fractal dimension determines

Sierpinski Carpet's theoretical fractal dimension $D=\frac{\ln 8}{\ln 3} \approx 1.8928$. As presented in Fig. 3b, the actual result we calculated is also 1.8928 , which indicates that the actual result is in good agreement with the theoretical value. In other words, this comparison confirms that our program

241 is feasible.

\section{$\underline{2.53 .2}$ Lattice Boltzmann method}

The second validation is carried out by simulating the flow of two-dimensional Poiseuille with different lattice sizes including $100 \times 100,250 \times 250$ and $500 \times 500$. The normalized streamwise velocity profiles $U=u / u_{\max }$ are compared with the analytical solution as shown in Fig. 4, which shows that the simulation results based on a series of lattice sizes are highly consistent with the analytical solutions. This consistency also confirms that the LBM is suitable for understanding the flow eapacitycapability.

\section{Results and discussion}

Micro-fracture morphology, pressure and temperature are three of the important factors affecting permeability and thus enhancing CBM recovery [39-41]. This section captured the flow characteristics of methane under different micro-fractures morphologies, different pressures and temperatures based on the $\mathrm{D} 2 \mathrm{Q} 9$ model. The pressure gradient was set to 0.1 $\mathrm{MPa} / \mathrm{m}$ in the simulation along the flow direction.

\subsection{Effects of micro-fracture morphology on flow eapacitycapability}

The pre-existing natural fractures characteristics are of importance on the hydraulic fracturing stimulation effect [7]. Herein, the effect of pre-existing natural fracture morphology on methane flow in coal will be discussed in detail. The velocity distribution results with different micro- 
that the pressure-driven methane migration in various micro-fracture networks is different. It is easy to find out that the existence of dominant channels is conducive to the gas flow-of methane, that is, there is a wide channel connecting the inlet to the outlet in the micro-fracture network fas shown by the red loted line-in Fig. 17. -The length and width of the dominant channel was counted intelisted in Table 2, and it is seen thatwhich has the average length and width areof $\sim 498.26 \mu \mathrm{m}$ and $10.96 \mu \mathrm{m}$, respectively. The velocity in the dominant channel is much larger compared with other locations (see Fig. 5). As shown in Fig. 5d and i, it gas flow is much more difficult for gas to flow if the micro-fracture network is connected by narrower channels fwith width less than $5 \mu \mathrm{m}$ ). Another interesting phenomenon is that the special micro-fracture morphology makes-determines the time when that the flow simulation reaches the steady state reatly different,, which varies from 5711 to 130561 showing greatly different. It can be found indicatedThis result means that the time for the simpler micro-fracture network takes ais much shorter time to reach the steady state, while the micro-fracture network with a more special shape (see-e.g., the orthogonal type in Fig. 5i and Fig. 6) and a more complex distribution (see Fig. $5 \mathrm{~g}$ ) takes longer to reach steady state. Assuming that $\mathrm{t}$ The equilibrium time-listed in Fig. 5 is used as the standard to evaluate the difficulty of fluid flow in micro-fracture network, it ean be seen the orthogonal micro-fracture is the unfavorable for flow capability, and the most favorable network is the-reticulartype. And in between are the dendritic and filamentous types are in between the orthogonal and reticular types. The dendritic type with more branches 

dimension and permeability with the correlation coefficient of 0.86 . The permeability increases 302

throats, itwhich result in is more difficult toflow in filamentous structure more difficult than that in the dendritic structuretype with fewer branches. More clearly, Fig. 6 indicates displays that the simulated flow process of the orthogonal micro-fracture network-is not easy for gas flow. At the beginning of the flow process, the gas will extend in three directions after meeting the bifurcation. As time goes on, the gas will flow further following with the branches. At this time, the upward and downward flow directions do not match the main flow direction; therefore, the gas in the up and down directions will gradually disappear. When the simulation reaches the steady state, the gas only passes in the main flow direction. The computation time also becomes longer due to the special angle (e.g., orthogonal type) of the branches inef the natural micro-fracture network.

The fracture dimension values calculated by $\mathrm{BCM}$ are displayed in Fig. 7 and, which ranges from 1.321 to-- 1.584 . The larger the value is, the more complicated the distribution of the natural micro-fracture network [16]. Besides, Fig. $8 \mathrm{~b}$ reveals that there is an obvious positive correlation between the fractal dimension and the fracture porosity. This phenomenon may be ascribed to two causes: the first is that micro-fracture network with lager fracture porosity will have a greater chance of being more complicated in-distribution, which is consistent with the conclusion of $-\mathrm{Wu}$ et al. [36]. Secondly, it is not significant that the micro-fracture network ebtained by optical miereseopy is-filled with minerals is poor developed, thus there is no complex trend that is similar to the relationship between porosity and fractal dimension_[35]. As shown in Fig. 8a, there is a significant inverted U-shaped relationship between fractal as fractal dimension increases from 1.321 to -1.472 , and then decreases as fractal dimension 
exceeds 1.472 . The permeability is $0.147 \mathrm{D}$ when the fractal dimension is 1.321 , while it

increases to $0.345 \mathrm{D}$ as fractal dimension reaches to 1.472 . The reason for this increasing trend

is that lower fractal dimension normally corresponds to lower fracture porosity, resulting in

lower permeability for methane. As the fractal dimension increases, the fracture porosity also increases, and the permeability is improved when the connectivity of the micro-fracture network is bettergood. However, when the fractal dimension exceeds 1.472 , it means that the micro-fracture network becomes more complex. Meanwhile, due to the strong heterogeneity of the CBM reservoir and poor connectivity $[1,26,42]$, the natural micro-fracture network is connected by the narrow throat, leading to difficult gas flow-of methane and thus lower permeability (as shown in Fig. 9). Fig. 9 shows that the methane still flows through the microfracture network branch $\mathrm{f} 1$ (see f2) at the beginning of the flow process, but methane will not pass through these channels as time increases. Hence, under the premise of only one flow direction, itthe flow time will undoubtedly make-take the flow time-longer if many branches exist in the micro-fracture network. And if the extension direction of these branches is different from the flow direction, they will be notit would constrainedconstrain contributed to the permeability.

\subsection{Effects of pressure on flow eapacity capability}

320 The trend of permeability together with outlet pressure is shown in Fig. 10-Fig. 10, which

321 illustrates that the permeability decreases sharply as pressure increases from $0.1 \mathrm{MPa}$ to $-5 \mathrm{MPa}$, 322 and then the change of permeability tends to be gentle-stable as pressure exceeds $5 \mathrm{MPa}$. In

323 other words, the natural micro-fracture network is more sensitive to change in permeability at 324 low pressure. This is because because-at low pressure, the distance between the rarefied gas 
molecules is far away and the attractive force is weak at low pressure [29]. The decreasing trend of decreasing permeability with increasing pressure is consistent with the production of shale gas production $[27,43]$. But in this study However, when the permeability is larger than $5 \mathrm{MPa}$, there is no similar trend similar to that in CBM production eoncludedby Shi and Durucan [44]. During the production of $-\mathrm{CBM}$ production, the permeability initially declines and then increases with increasing pressure $[6,44]$. The reason for this phenomenon is that the shrinkage of the coal matrix due to gas desorption, a unique a unique characteristic of coal reservoir, counteracts the decrease in permeability decrease with pressure drop during the production [4, 45]. Therefore, a model considering matrix swelling/shrinkage can accurately describe gas actual flow characteristics. Due to its extremely challenging nature, coal matrix

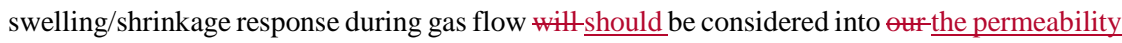
model in the near future.

43.3 Effects of temperature on flow eapacity capability

Three sets of temperatures were simulated to study the effects of ehanges of -temperature changes including $300 \mathrm{~K}, 330 \mathrm{~K}$ and $360 \mathrm{~K}$ on coalte permeability, including $300 \mathrm{~K}, 330 \mathrm{~K}$ and 360 K. From-Fig. 10, it can be seen exhibits that the permeability will-increase with increasing temperature for at the constant pressure. The increase of temperature will aggravate the thermal motion of gas molecules, leading to the average kinetic energy of the molecules increasing and thereby increasing the permeability, which is in accordance with the research conclusion of Yuan et alprevious research- [29]. And at low pressure, the influence of temperature on permeability is more sensitive-at low pressure. For realistic CBM production, the effect of temperature on coal permeability is related to many factors, such as coal rank and pore-fracture
Formatted: Font color: Auto

Formatted: Font color: Auto 
structure [39, 42]. For instance, Cai et al. [39] revealed that different rank coals have different

trends in permeability changes caused by temperature. And Liu et al. [42] studied found that

349 the effect of -temperature has obvious impact on the mechanical properties and acoustic emission characteristics in coal, and found that the pore-fracture structures were promoted and the permeability was significantly improved under the impact of temperature treatment. Therefore, the micro-fracture morphology, pressure and temperature have an comprehensive complex influence on the gas flow capability, which generally follows the dominated microfracture morphology, supplemented by pressure and temperature., Tthe comprehensive mechanism is shown in Fig. 11. CBM reservoirs normally have the characteristics of complex pore-fracture structure, strong heterogeneity, and abundant mineral types, which may cause a series of physical and chemical changes in the process of temperature increase [46]. Even, dDifferent components in coal have different shrinking and swelling ability under the effect of temperature [42]. For example, the temperature stress will aggravate the expansion of fractures and weaken the mechanical properties of coal [42]. $X X$ and $X X$. Moreover, during the exploitation of CBM, the reservoir temperature also changes dynamically with produced gases; thus, the effect of temperature on permeability must-should be cautiously considered [47]. Therefore, the micro-fracture morphology, pressure and temperature have a comprehensive complex influence on gas flow capability, which generally follows the dominated microfracture morphology, supplemented by pressure and temperature. The comprehensive mechanism is as shown in Fig. 11.

Although the detailed work on the morphology effect of micro-fracture network on permeability has been revealed, the process of fluid-solid coupling has yet to confirm, which 
370 heat transmission. Therefore, the flow response in micro-nano scale natural pore-fracture

371 structure during the expleitation of CBM development will be our next foeus in the following

372 work.

373 5. Conclusions

374 In this study, natural micro-fracture morphologies of selected Chinese coals from the Ordos

Basin were characterized by the optical microscope. And the box-counting method together with the lattice Boltzmann method was adopted to quantify the complexity of the micro-fracture network and to investigate the-flow behaviors in these natural micro-fracture networks. Besides, factors affecting the flow eapacity capability in these natural micro-fracture networks were discussed. The following conclusions can be summarizedmade:

380 1) The existence of dominant channels in the natural micro-fracture network will greatly improve the permeability. Besides, the-flow characteristics ef-in the micro-fracture networks with different morphologies are quite different, which presents that the orthogonal type is unfavorable for flow capability, and the most favorable network is reticular, with dendritic and

2) An obvious inverted U-shaped relationship exists between the fractal dimension and permeability. When the fractal dimension is lower than 1.472 , the larger fractal dimension means the greater fracture porosity, and thus the permeability of well-connected natural microfractures will be-increased. When-As the fractal dimension exceeds 1.472 , the distribution of natural micro-fracture network is eomplieatedcomplicated, which presents reticular and dendritic types $X X$. a And the connected narrow throats normally lead to a permeability decrease. 
3) Pressure and temperature have opposite influence on coal permeability. The permeability

increases with decreasing gas? pressure, which is caused by due to-the rarefied gas eaused

bydue to the declining pressure. But $\underline{H o w e v e r, ~ t h e ~ m e t h a n e-g a s ~ a t ~ h i g h ~ t e m p e r a t u r e s ~ o f ~} \mathrm{XX} 360$ $\underline{\mathrm{K}}$ will lead to a $n g$ gentle increase of permeability.

\section{Acknowledgements}

This research was funded by the National Natural Science Foundation of China (grant nos. 41830427, 41922016 and 41772160) and the Fundamental Research Funds for Central Universities (grant no. 2652019255). The authors also want to thank the Royal Society Edinburgh and NSFC to support their collaborations.

\section{References}

[1] Moore TA. Coalbed methane: A review. Int J Coal Geol 2012;101:36-81.

[2] Vishal V, Singh TN, Ranjith PG. Influence of sorption time in CO2-ECBM process in Indian coals using coupled numerical simulation. Fuel 2015;139:51-8.

[3] Jia D, Qiu YK, Li C, Cai YD. Propagation of pressure drop in coalbed methane reservoir during drainage stage. Advances in Geo-Energy Research 2019;3(4):387-95.

[4] Cai YD, Li Q, Liu DM, Zhou YF, Lv DW. Insights into matrix compressibility of coals by mercury intrusion porosimetry and N-2 adsorption. Int J Coal Geol 2018;200:199212.

[5] Laubach SE, Marrett RA, Olson JE, Scott AR. Characteristics and origins of coal cleat: A review. Int J Coal Geol 1998;35(1-4):175-207.

[6] Pan ZJ, Connell LD. Modelling permeability for coal reservoirs: A review of analytical models and testing data. Int J Coal Geol 2012;92:1-44.

[7] Yao WL, Mostafa S, Yang Z, Xu G. Role of natural fractures characteristics on the performance of hydraulic fracturing for deep energy extraction using discrete fracture network (DFN). Engineering Fracture Mechanics 2020;230.

[8] Zheng SJ, Yao YB, Liu DM, Cai YD, Liu Y. Nuclear magnetic resonance surface relaxivity of coals. Int J Coal Geol 2019;205:1-13.

[8] Liu ZS, Liu DM, Cai YD, Yao YB, Pan ZJ, Zhou YF. Application of nuclear magnetic resonance (NMR) in coalbed methane and shale reservoirs: A review. Int J Coal Geol $2020 ; 218$

[9] Harmer J, Callcott T, Maeder M, Smith BE. A novel approach for coal characterization by NMR spectroscopy: global analysis of proton $\mathrm{T} 1$ and $\mathrm{T} 2$ relaxations. Fuel 2001;80(3):417-25.

[10] Mathews JP, Campbell QP, Xu H, Halleck P. A review of the application of X-ray 
computed tomography to the study of coal. Fuel 2017;209:10-24.

[11] Balucan RD, Turner LG, Steel KM. X-ray mu CT investigations of the effects of cleat demineralization by $\mathrm{HCl}$ acidizing on coal permeability. J Nat Gas Sci Eng 2018;55:206-18

[11] Ramandi HL, Mostaghimi P, Armstrong RT, Saadatfar M, Pinezewski WV. Poresity and permeability characterization of coal: a miero-computed tomography study. Int $J$ Coal Geol 2016;154:57 68.

[12] Roslin A, Pokrajac D, Zhou YF. Cleat structure analysis and permeability simulation of coal samples based on micro-computed tomography (micro-CT) and sean electron microscopy (SEM) technology. Fuel 2019;254:115579.

[12] Jenkins DR, Lomas H, Mahoney M. Uniaxial compression of metallurgical coke samples with progressive loading. Fuel 2018;226:163-71.

[13] Cai YD, Liu DM, Pan ZJ, Che Y, Liu ZH. Investigating the effects of seepage-pores and fractures on coal permeability by fractal analysis. Transport Porous Med 2016;111(2):479-97.

[14] Lu Y, J., Liu D, M., Cai Y, D., Li Q, Jia Q, F. Pore fractures of coalbed methane reservoir restricted by coal facies in Sangjiang Muling Coal Bearing Basins, Northeast China. Energies 2020;13(1196).

[14] Mahnke M, Mögel HJ. Fractal analysis of physical adsorption on material surfaces. Colloids and Surfaces A: Physicochemical and Engineering Aspects 2003;216(13):215-28.

[15] Peng C, Zou CC, Yang YQ, Zhang GH, Wang WW. Fractal analysis of high rank coal from southeast Qinshui basin by using gas adsorption and mercury porosimetry. J Petrol Sci Eng 2017;156:235-49.

[16] Liu XF, Nie BS. Fractal characteristics of coal samples utilizing image analysis and gas adsorption. Fuel 2016;182:314-22.

[16] Saif T, Lin QY, Butcher AR, Bijeljic B, Blunt MJ. Multi-seale multi-dimensional microstructure imaging of oil shale pyrolysis using $\mathrm{X}$-ray micro-tomography, automated ultra-high resolution SEM, MAPS Mineralogy and FIB-SEM. Appl Energ 2017:202:628-47.

[17] Lopes R, Betrouni N. Fractal and multifractal analysis: A review. Medical Image Analysis 2009;13(4):634-49.

[18] Liu P, Qin YP, Liu SM, Hao YJ. Modeling of gas flow in coal using a modified dualporosity model: a multi-mechanistic approach and finite difference method. Rock Mechanics and Rock Engineering 2018;51(9):2863-80.

[19] Sun Z, Loge RE, Bernacki M. 3D finite element model of semi-solid permeability in an equiaxed granular structure. Computational Materials Science 2010;49(1):158-70.

[20] Almasoodi M, Reza Z. Finite-volume computations of shale tortuosity and permeability from $3 \mathrm{~d}$ pore networks extracted from scanning electron tomographic images. Petrophysics 2019;60(3):397-408.

[21] Aidun CK, Clausen JR. Lattice-Boltzmann method for complex flows. Annual Review of Fluid Mechanics 2010;42:439-72.

[22] Liu HH, Kang QJ, Leonardi CR, Schmieschek S, Narvaez A, Jones BD, et al. Multiphase lattice Boltzmann simulations for porous media applications. 
Computational Geosciences 2016;20(4):777-805.

[23] Wang M, Chen YF, Ma GW, Zhou JQ, Zhou CB. Influence of surface roughness on nonlinear flow behaviors in 3D self-affine rough fractures: Lattice Boltzmann simulations. Adv Water Resour 2016;96:373-88.

[24] Zhao YL, Wang ZM, Ye JP, Sun HS, Gu JY. Lattice Boltzmann simulation of gas flow and permeability prediction in coal fracture networks. J Nat Gas Sci Eng 2018;53:15362.

[25] Zhao YL, Wang ZM, Qin X, Li JT, Yang H. Stress-dependent permeability of coal fracture networks: A numerical study with Lattice Boltzmann method. J Petrol Sci Eng 2019;173:1053-64.

[26] Jing Y, Armstrong RT, Mostaghimi P. Image-based fracture pipe network modelling for prediction of coal permeability. Fuel 2020;270.

[26] Zhou SD, Liu DM, Cai YD, Yao YB, Li ZT. 3D characterization and quantitative evaluation of pore-fracture networks of two Chinese coals using FIB-SEM tomography. Int J Coal Geol 2017:174:41-54.

[27] Wang JJ, Kang QJ, Chen L, Rahman SS. Pore-scale lattice Boltzmann simulation of micro-gaseous flow considering surface diffusion effect. Int J Coal Geol 2017;169:6273.

[28] Gupta N, Fathi E, Belyadi F. Effects of nano-pore wall confinements on rarefied gas dynamics in organic rich shale reservoirs. Fuel 2018;220:120-9.

[29] Yuan YD, Wang YZ, Rahman SS. Reconstruction of porous structure and simulation of non-continuum flow in shale matrix. J Nat Gas Sci Eng 2017;46:387-97.

[30] Yao YB, Liu DM. Microscopic characteristics of microfractures in coals: an investigation into permeability of coal. Procedia Earth and Planetary Science 2009;1(1):903-10.

[31] International Committee for Coal and Organic Petrology (ICCP). The new vitrinite classifcation (ICCP System 1994). Fuel 1998;77(5):349-58.

[32] Zhou HW, Xie H. Direct estimation of the fractal dimensions of a fracture surface of rock. Surf Rev Lett 2003;10(5):751-62.

[33] Mandelbrot BB. The fractal geometry of nature. Sciences 1983;23(5):63-8.

[34] Ai T, Zhang R, Zhou HW, Pei JL. Box-counting methods to directly estimate the fractal dimension of a rock surface. Appl Surf Sci 2014;314:610-21.

[35] Li Q, Liu DM, Cai YD, Zhao B, Qiu YK, Zhou YF. Scale-span pore structure heterogeneity of high volatile bituminous coal and anthracite by FIB-SEM and X-ray u-CT. J Nat Gas Sci Eng 2020;81:103443.

[36] Wu H, Zhou YF, Yao YB, Wu KJ. Imaged based fractal characterization of microfracture structure in coal. Fuel 2019;239:53-62.

[37] Bhatnagar PL, Gross EP, Krook M. A model for collision processes in gases. i. small amplitude processes in charged and neutral one-component systems. Physical Review 1954;94(3):511-25.

[38] Qian YH, D'Humières D, Lallemand P. Lattice BGK models for Navier-Stokes equation. Europhysics Letters (EPL) 1992;17(6):479-84.

[39] Cai YD, Pan ZJ, Liu DM, Zheng GQ, Tang SH, Connell LD, et al. Effects of pressure and temperature on gas diffusion and flow for primary and enhanced coalbed methane 
recovery. Energ Explor Exploit 2014;32(4):601-19.

[40] Wang G, Han DY, Jiang CH, Zhang ZY. Seepage characteristics of fracture and deadend pore structure in coal at micro- and meso-scales. Fuel 2020;266.

[41] Mostaghimi P, Armstrong RT, Gerami A, Hu YB, Jing Y, Kamali F, et al. Cleat-scale characterisation of coal: An overview. J Nat Gas Sci Eng 2017;39:143-60.

[42] Liu SM, Li XL, Wang DK, Wu MY, Yin GZ, Li MH. Mechanical and acoustic emission characteristics of coal at temperature impact. Natural Resources Research 2020;29(3):1755-72.

[43] Cui G, Liu J, Wei M, Shi R, Elsworth D. Why shale permeability changes under variable effective stresses: New insights. Fuel 2018;213:55-71.

[44] Shi JQ, Durucan S. Exponential growth in San Juan Basin Fruitland coalbed permeability with reservoir drawdown: Model match and new insights. Spe Reserv Eval Eng 2010;13(6):914-25.

[45] Gray I. Reservoir Engineering in Coal Seams: Part 1-The physical process of gas storage and movement in coal seams. SPE-12514-PA 1987;2(01):28-34.

[46] Sharma A, Kyotani T, Tomita A. Quantitative evaluation of structural transformations in raw coals on heat-treatment using HRTEM technique. Fuel 2001;80(10):1467-73.

[47] Liu SY, Wei CH, Zhu WC, Zhang M. Temperature- and pressure-dependent gas diffusion in coal particles: Numerical model and experiments. Fuel 2020;266. 
Fig. 1. Different micro-fracture morphologies of selected samples obtained by optical microscope, which varied involving dendritic, reticular, filamentous and orthogonal etc. The red dotted lines are the dominant channels mentioned in section 4.1

Fig. 2. The results after threshold segmentation and the discrete velocity of D2Q9 model. (a) is the initial image; (b) and (c) are images before and after noise reduction, respectively. Careful observation shows that the noise in the red rectangular frame of (c) is significantly less than that in (b), and the edge of the micro-fracture in (c) is smoother after noise reduction. (d) is the discrete velocity of D2Q9 model-.

Fig. 3. The verification of the box-counting method. (a) is the Sierpinski Carpet image and (b) is the value estimated by the box-counting method.

Fig. 4. Normalized streamwise velocity profiles with different lattice sizes.

Fig. 5. The velocity distribution results of dimensionless lattice unit when the simulation reaches equilibrium with different micro-fractures morphologies and the schematic diagram of the gas flow model. $t$ is the time for the simulation to reach convergence. (a)- (i) are the velocity distribution results and (j) is the schematic diagram of the gas flow model. Simulation conditions include $\mathrm{T}=300 \mathrm{~K}$, outlet pressure $=10 \mathrm{MPa}$ and pressure gradient $=0.1 \mathrm{MPa} / \mathrm{m}$.

Fig. 6. Velocity distribution of sample F9 under different time steps. $t$ is the time step. The length of the arrow indicates how far the gas flows. At the beginning of the flow process, the gas will extend in three directions after meeting the bifurcation. As time goes on, the gas will flow further following with the branches. At this time, the upward and downward flow directions do not match the main flow direction, so the gas in the up and down directions will 
gradually disappear. When the simulation reaches equilibrium, the gas only passes in the main type) of the branches of the microfracture network. Simulation conditions include $\mathrm{T}=300 \mathrm{~K}$, outlet pressure $=10 \mathrm{MPa}$ and pressure gradient $=0.1 \mathrm{MPa} / \mathrm{m}$.

Fig. 7. Results of fractal dimension calculated by the box-counting method

Fig. 8. Relations between permeability, fracture porosity and fractal dimension. (a) fractal dimension versus permeability and (b) fractal dimension versus fracture porosity. $\mathrm{T}=300 \mathrm{~K}$, outlet pressure $=10 \mathrm{MPa}$ and pressure gradient $=0.1 \mathrm{MPa} / \mathrm{m}$.

Fig. 9. Velocity distribution of sample F7 under different time steps. $t$ is the time step. (a) is the initial image of F7 and (b)-(e) are the velocity distribution under different time steps during simulation. $\mathrm{f} 1$ and $\mathrm{f} 2$ are the original image of the branch and the changes that occurred in the branch during the flow process, respectively.

Fig. 10. Relations between pressure, temperature and permeability in different samples. Pressure gradient $=0.1 \mathrm{MPa} / \mathrm{m}$.

Fig. 11. Diagram of the influence mechanism of different factors on permeability, including the micro-fracture morphology, pressure and temperature. The positive and negative signs ("+" and “-”) in the figure represent the promotion and inhibition effects, respectively.

Table 1 Sample information and basic parameters of the selected coals. 


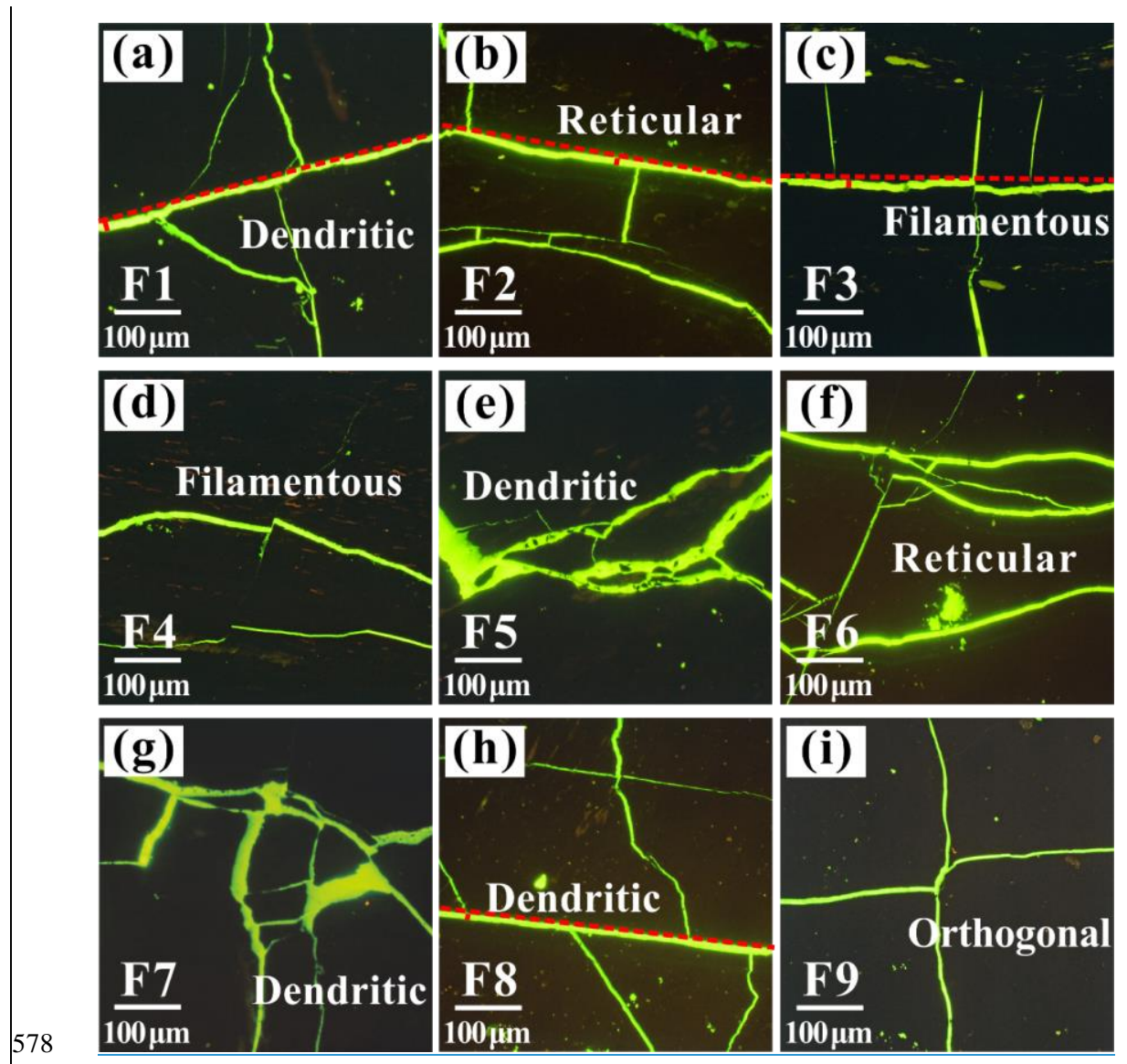

579 Fig. 1. Different micro-fracture morphologies of selected samples obtained by optical microscope,

580 which varied involving dendritic, reticular, filamentous and orthogonal etc. The red dotted lines are 581

the dominant channels mentioned in section $4 \underline{3} .1$. 

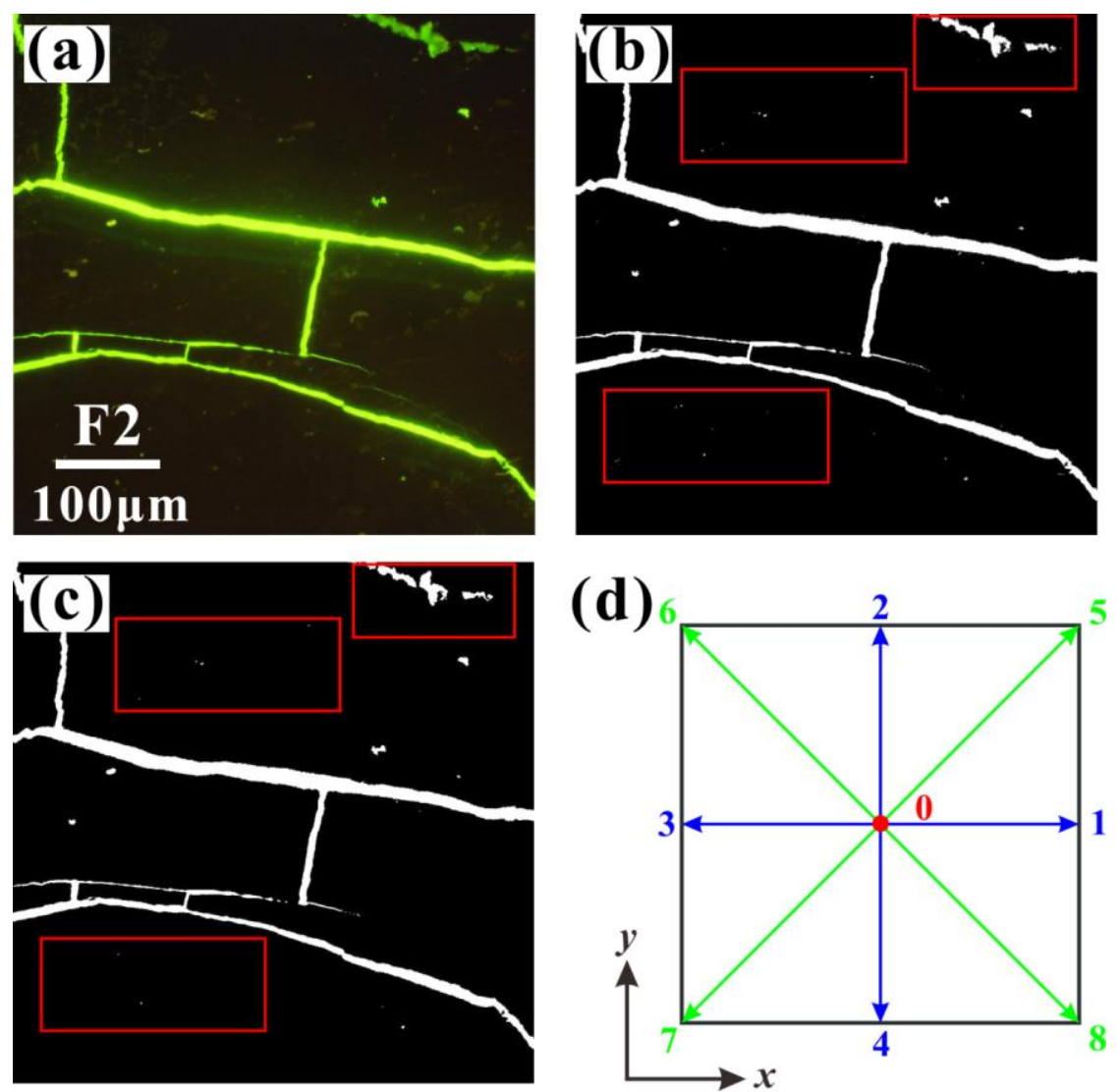

Fig. 2. The results after threshold segmentation and the discrete velocity of D2Q9 model. (a) is the

observation shows that the noise in the red rectangular frame of (c) is significantly less than that in 


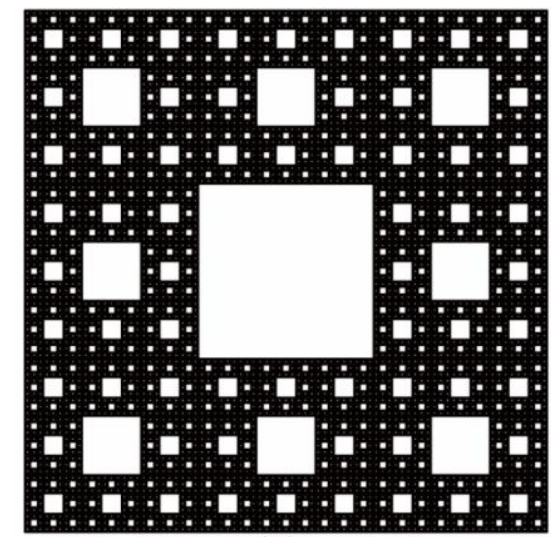

(a)

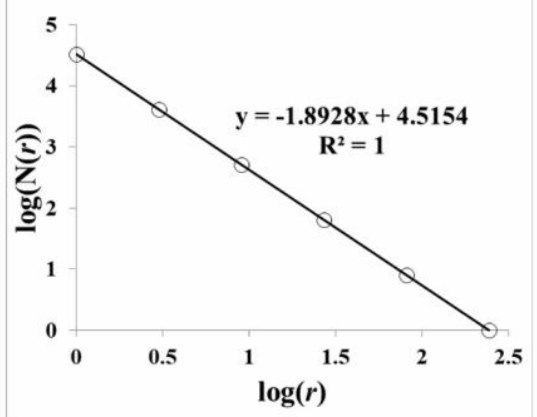

(b)

Fig. 3. The verification of the box-counting method. (a) is the Sierpinski Carpet image and (b) is 


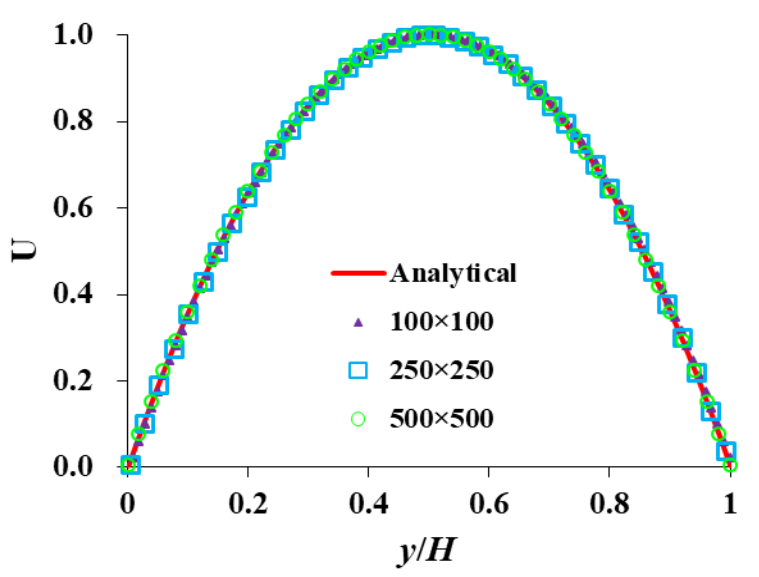

595

596 Fig. 4. Normalized streamwise velocity profiles with different lattice sizes. 

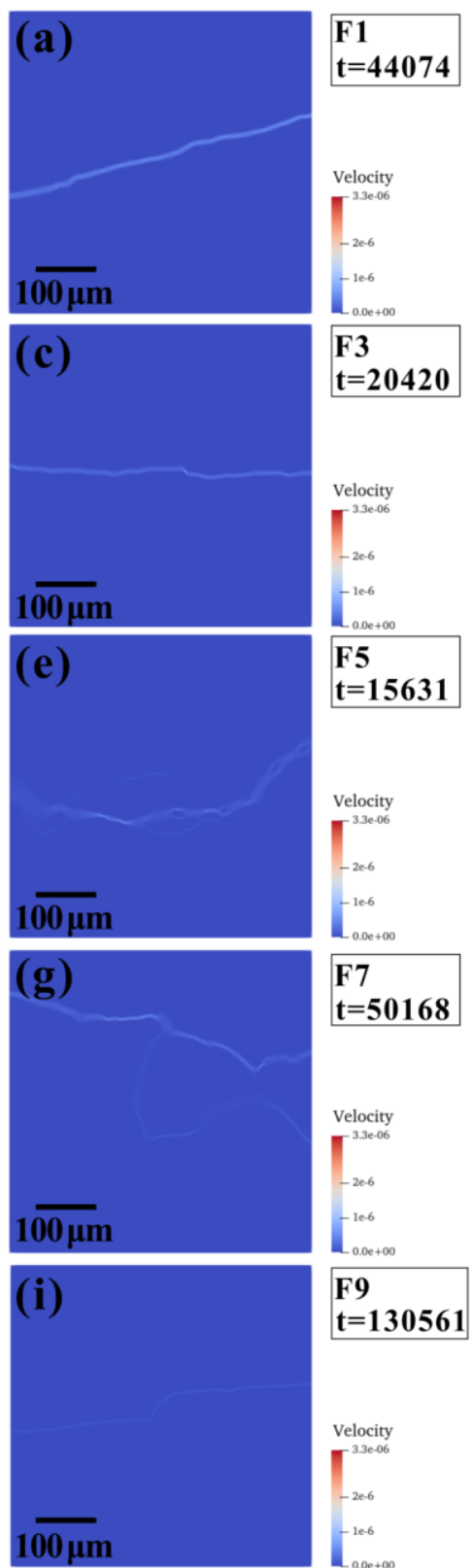

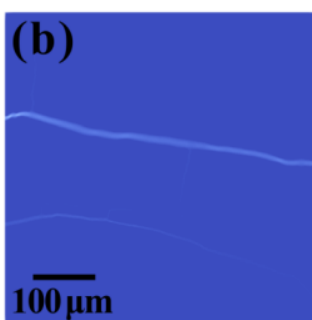

F2

$\mathbf{t}=\mathbf{5 7 1 1}$

Velocity

$\pi^{-3.3 e-06}$
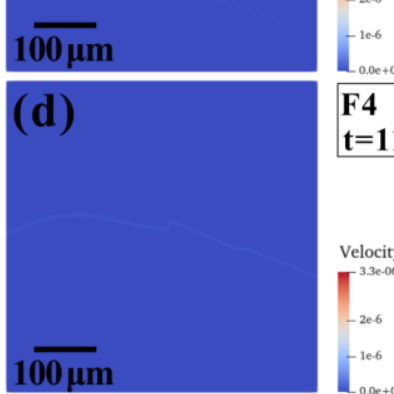

F4

$\mathbf{t}=\mathbf{1 1 7 3 0}$

Velocity

$T^{3.3 e-06}$
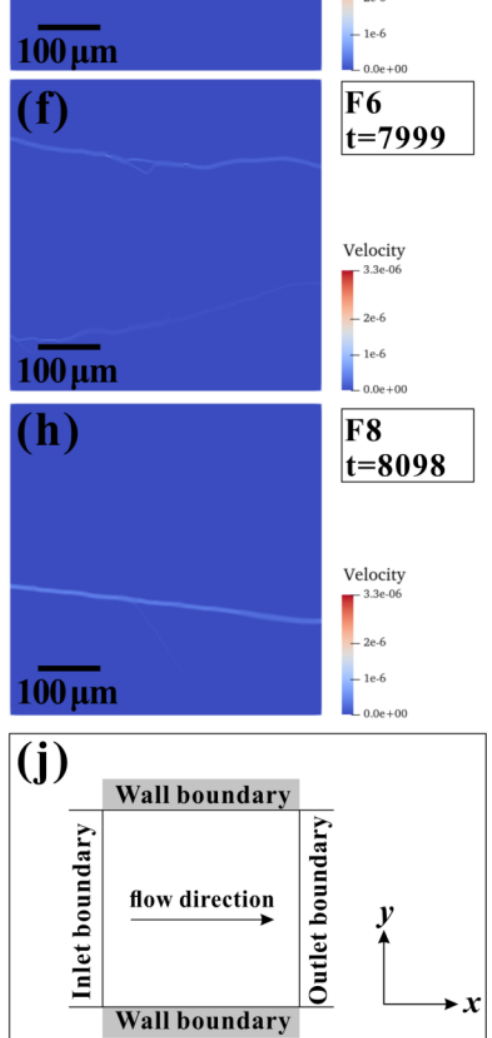

Fig. 5. The velocity distribution results of dimensionless lattice unit when the simulation reaches equilibrium with different micro-fractures morphologies and the schematic diagram of the gas flow model. $t$ is the time for the simulation to reach convergence. (a)- (i) are the velocity distribution results and (j) is the schematic diagram of the gas flow model. Simulation conditions include $\mathrm{T}=$ $300 \mathrm{~K}$, outlet pressure $=10 \mathrm{MPa}$ and pressure gradient $=0.1 \mathrm{MPa} / \mathrm{m}$. 

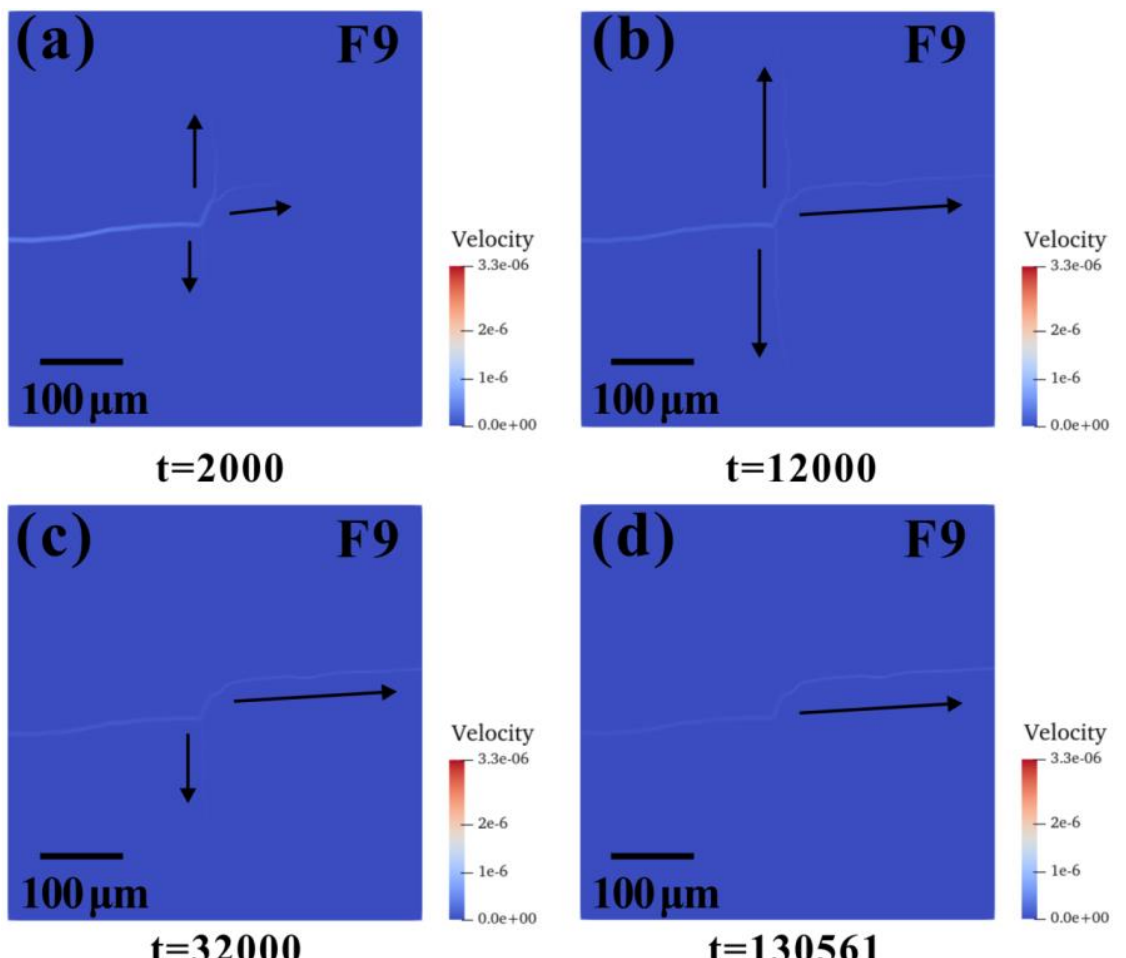

Fig. 6. Velocity distribution of sample F9 under different time steps. $t$ is the time step. The length

of the arrow indicates how far the gas flows. At the beginning of the flow process, the gas will extend in three directions after meeting the bifurcation. As time goes on, the gas will flow further following with the branches. At this time, the upward and downward flow directions do not match the main flow direction, so the gas in the up and down directions will gradually disappear. When the simulation reaches equilibrium, the gas only passes in the main flow direction. The equilibrium

611 time also becomes longer due to the special angle (orthogonal type) of the branches of the microfracture network. Simulation conditions include $\mathrm{T}=300 \mathrm{~K}$, outlet pressure $=10 \mathrm{MPa}$ and pressure gradient $=0.1 \mathrm{MPa} / \mathrm{m}$.

614 

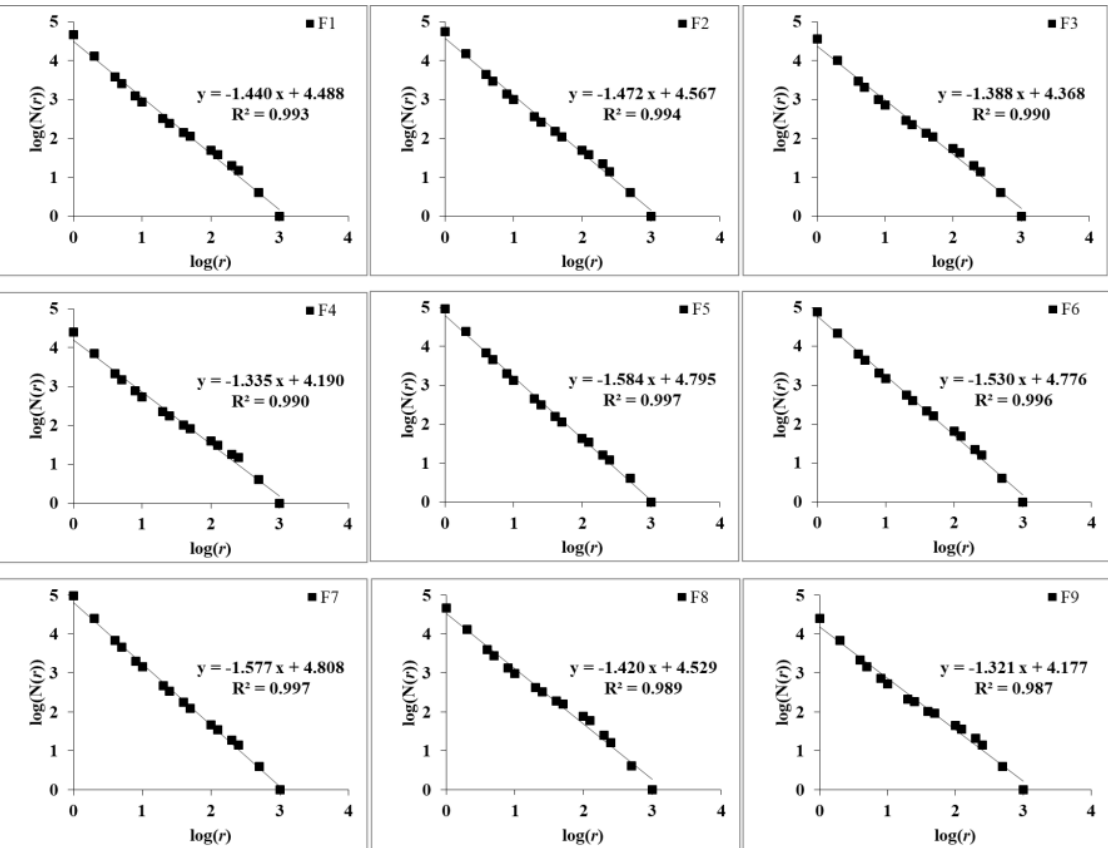

Fig. 7. Results of fractal dimension calculated by the box-counting method 

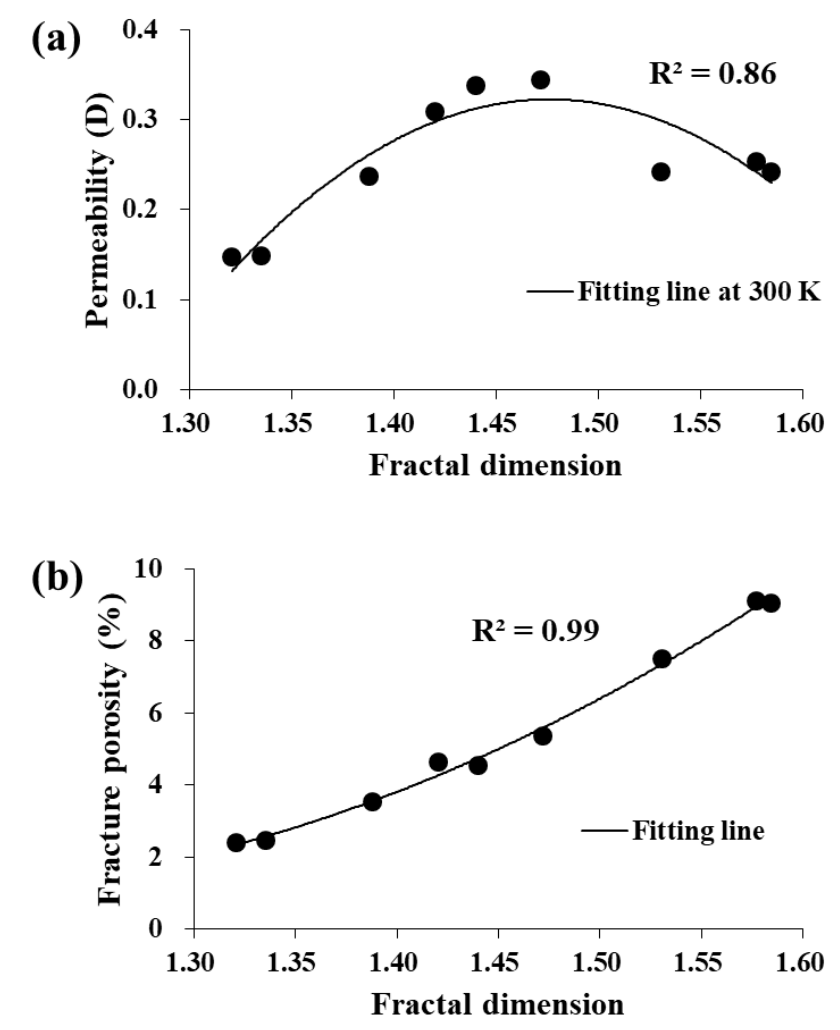

619 Fig. 8. Relations between permeability, fracture porosity and fractal dimension. (a) fractal dimension versus permeability and (b) fractal dimension versus fracture porosity. $\mathrm{T}=300 \mathrm{~K}$, outlet

621 pressure $=10 \mathrm{MPa}$ and pressure gradient $=0.1 \mathrm{MPa} / \mathrm{m}$. 


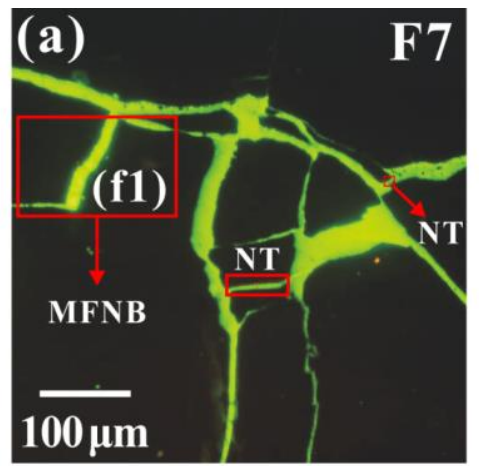

NT: Narrow throats

MFNB: Micro-fracture network branch
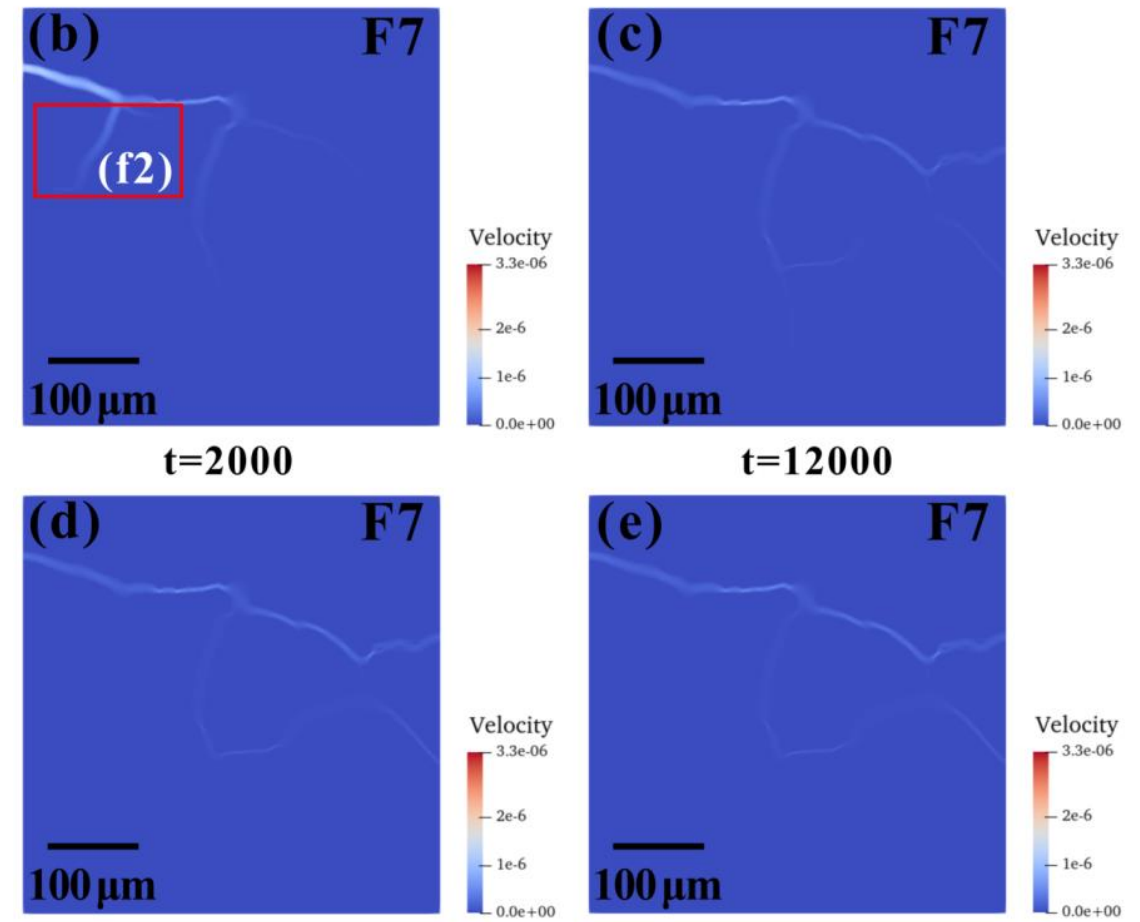
$\mathbf{t}=\mathbf{3 2 0 0 0}$

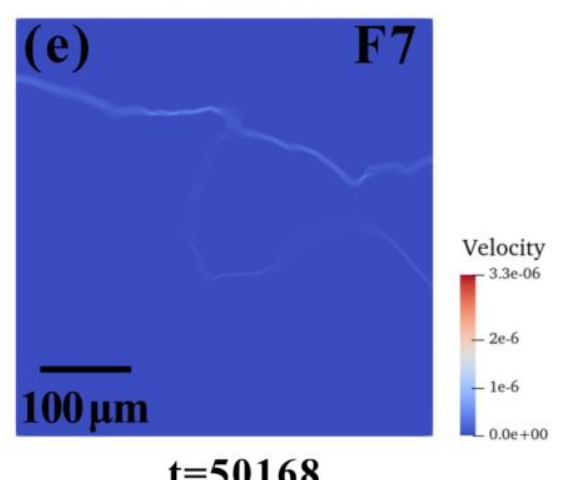

Fig. 9. Velocity distribution of sample F7 under different time steps. $t$ is the time step. (a) is the

initial image of F7 and (b)-(e) are the velocity distribution under different time steps during

simulation. $\mathrm{f} 1$ and $\mathrm{f} 2$ are the original image of the branch and the changes that occurred in the branch

during the flow process, respectively.

628 


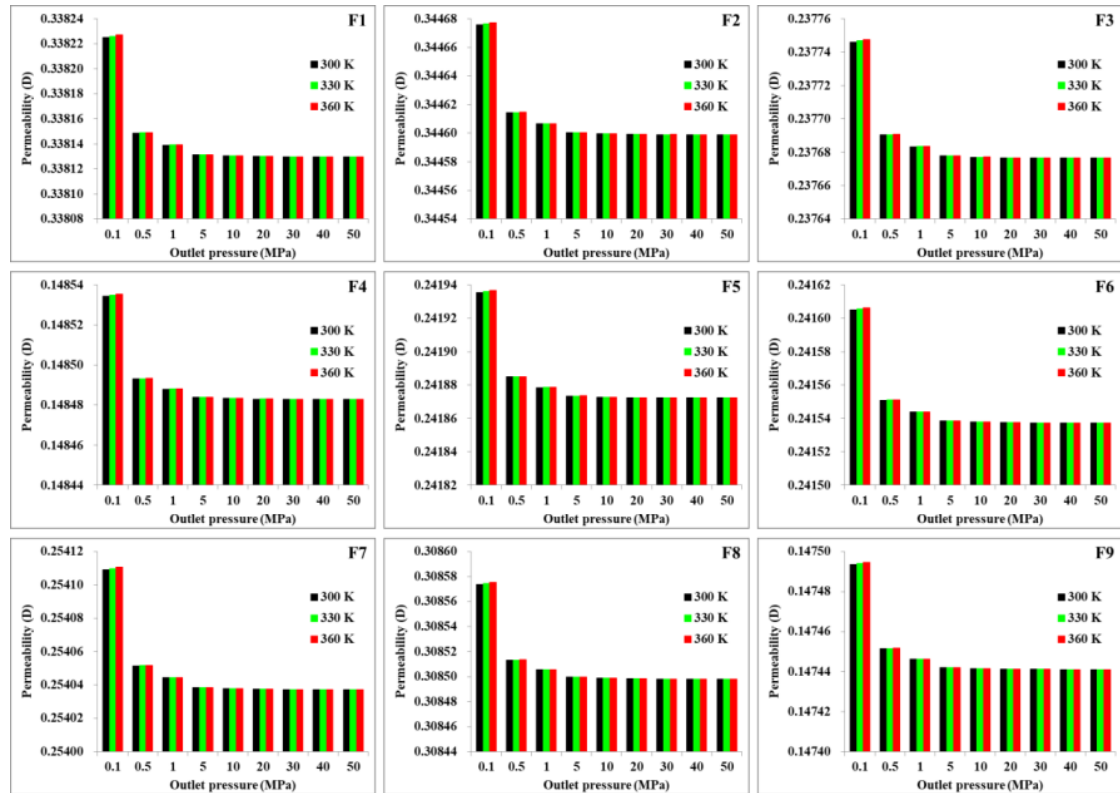

630 Fig. 10. Relations between pressure, temperature and permeability in different samples. Pressure 


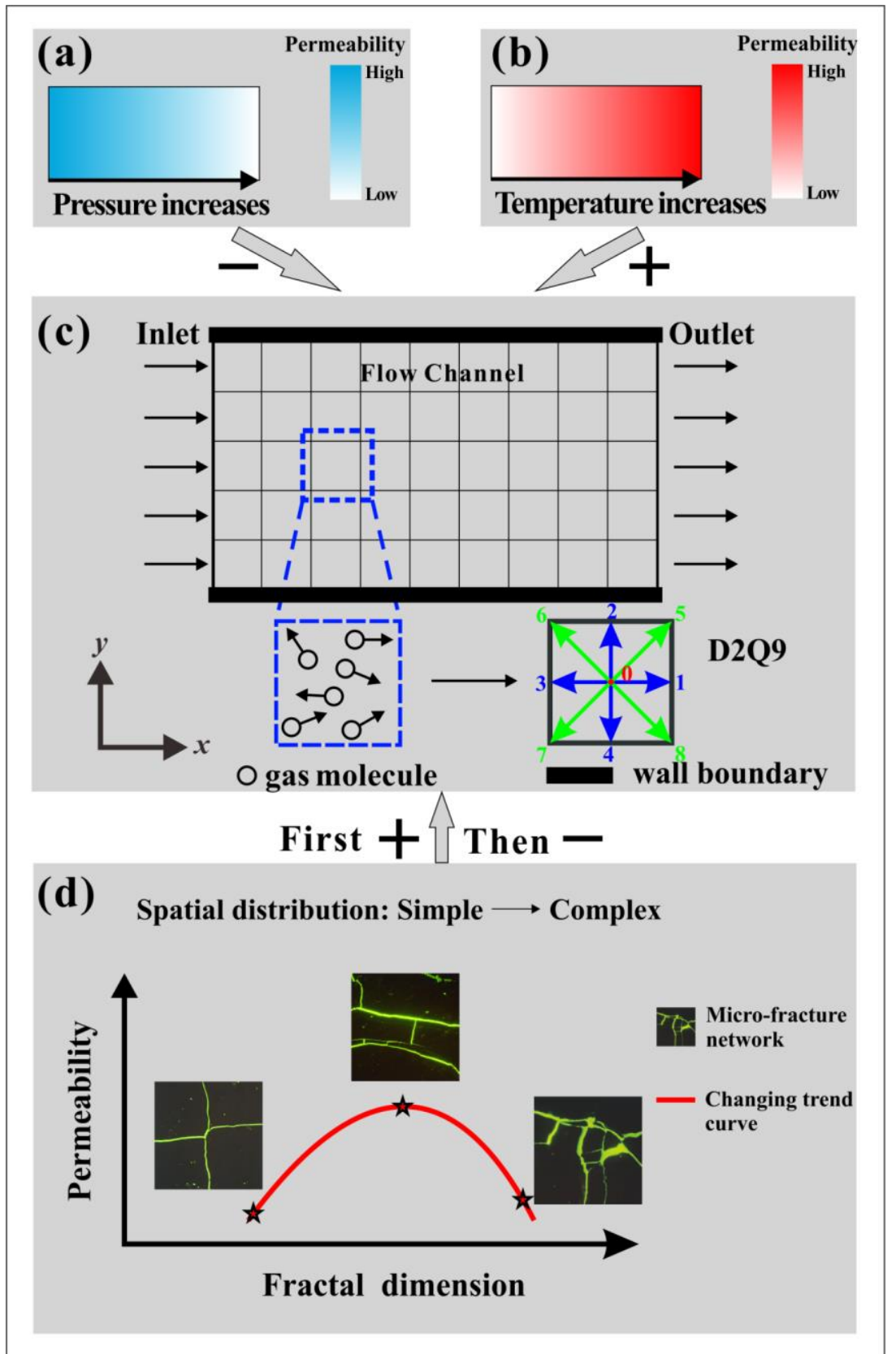

Fig. 11 Diagram of the influence mechanism of different factors on permeability, including the micro-fracture morphology, pressure and temperature. The positive and negative signs ("“+” and "-") in the figure represent the promotion and inhibition effects, respectively. 
Table 1 Sample information and basic parameters of the selected coals

\begin{tabular}{|c|c|c|c|c|c|c|c|}
\hline \multirow{2}{*}{$\begin{array}{c}\text { Sample } \\
\text { no. }\end{array}$} & \multirow{2}{*}{ Basin } & \multirow{2}{*}{$\begin{array}{c}\mathrm{R}_{\mathrm{o}, \max } \\
(\%)\end{array}$} & \multicolumn{4}{|c|}{ Maceral and mineral (\%) } & \multirow{2}{*}{$\begin{array}{l}\text { Fracture porosity } \\
\qquad(\%)\end{array}$} \\
\hline & & & Vitrinite & Inertinite & Exinite & Mineral & \\
\hline $\mathrm{F} 1$ & & 0.62 & 65.4 & 21 & 5.3 & 8.3 & 4.53 \\
\hline $\mathrm{F} 2$ & & 0.65 & 66.2 & 24.9 & 1.4 & 7.5 & 5.35 \\
\hline F3 & & 0.68 & 90.1 & 4.5 & 4.4 & 1 & 3.54 \\
\hline $\mathrm{F} 4$ & & 0.89 & 66.9 & 25.6 & 5.9 & 1.6 & 2.45 \\
\hline F5 & Ordos & 1.27 & 90.2 & 8.3 & 0 & 1.5 & 9.05 \\
\hline F6 & & 1.27 & 82.3 & 14.7 & 0 & 3 & 7.50 \\
\hline F7 & & 1.36 & 82.2 & 15.2 & 2.4 & 0.2 & 9.11 \\
\hline F8 & & 1.58 & 84.0 & 11.6 & 0.6 & 3.8 & 4.64 \\
\hline F9 & & 1.78 & 84.4 & 7.9 & 3.1 & 4.6 & 2.41 \\
\hline
\end{tabular}

639

640 Table 2 Statistics of the length and width for the dominant channel of micro-fractures in Fig. 1.

\begin{tabular}{c|cccc|c}
\hline$\underline{\text { Figure ID }}$ & $\underline{\text { Fig 1(a) }}$ & $\underline{\text { Fig 1(b) }}$ & $\underline{\text { Fig 1(c) }}$ & $\underline{\text { Fig 1(h) }}$ & $\underline{\text { Average }}$ \\
\hline$\underline{\text { Length }(\mu \mathrm{m})}$ & $\underline{506.66}$ & $\underline{495.61}$ & $\underline{493.68}$ & $\underline{497.10}$ & $\underline{498.26}$ \\
$\underline{\text { Width }(\mu \mathrm{m})}$ & $\underline{13.63}$ & $\underline{10.19}$ & $\underline{11.13}$ & $\underline{8.88}$ & $\underline{10.96}$ \\
\hline
\end{tabular}

64

642 


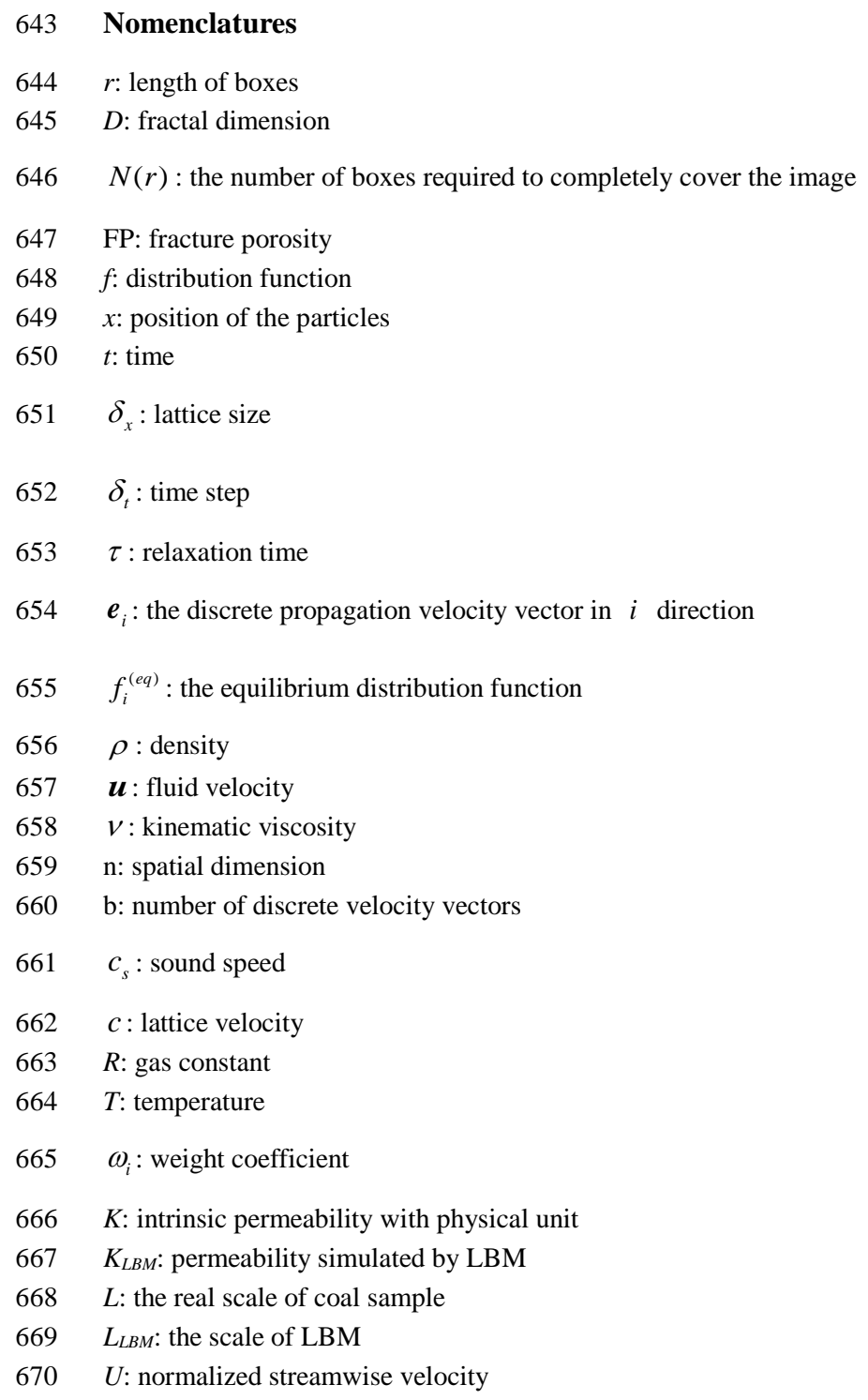


1 Effects of natural micro-fracture morphology, temperature and pressure on

2 fluid flow in coals through fractal theory combined with lattice Boltzmann

3 method

4 Qian $\mathrm{Li}^{\mathrm{a}, \mathrm{b}}$, Dameng Liu ${ }^{\mathrm{a}, \mathrm{b}}$, Yidong Cai ${ }^{\mathrm{a}, \mathrm{b}^{*}}$, Bo Zhao ${ }^{\mathrm{c}}$, Yuejian Lu ${ }^{\mathrm{a}, \mathrm{b}}$, Yingfang Zhou ${ }^{\mathrm{d}}$

$5 \quad{ }^{a}$ School of Energy Resources, China University of Geosciences, Beijing 100083, China

${ }^{b}$ Coal Reservoir Laboratory of National Engineering Research Center of CBM Development \& Utilization, China

University of Geosciences, Beijing 100083, China

${ }^{c}$ School of Water Resources and Environment, China University of Geosciences, Beijing 100083, China

${ }^{d}$ School of Engineering, Fraser Noble Building, King's College, University of Aberdeen, AB24 $3 U E$ Aberdeen, UK

\section{Abstract}

11 The fluid flow behaviors during the production of coalbed methane (CBM) are generally restricted by the pre-existing natural fractures in coal seams. To better understand the effect of natural micro-fracture morphology on the flow capability, nine coals collected from Ordos Basin were subjected to optical microscope observations to obtain micro-fractures morphology. And then, an improved box-counting method (BCM) was used to quantify the complexity of the micro-fracture network planar distribution. Besides, the lattice Boltzmann method (LBM) was adopted to simulate the flow in the complex micro-fracture network under different pressures and temperatures. Finally, factors affecting the flow capability in micro-fracture were

19 elaborated. The results show that the micro-fractures generally present dendritic, reticular,

20 filamentous and orthogonal structures. The natural micro-fracture morphology has a 21 remarkable impact on flow behavior, in which the presence of dominant channels with a length

\footnotetext{
* Corresponding author, Email address: yidong.cai@cugb.edu.cn (Y. Cai)
} 
of $\sim 498.26 \mu \mathrm{m}$ and a width of $\sim 10.96 \mu \mathrm{m}$ has a significant contribution to permeability, while the orthogonal micro-fracture network normally is not conducive to fluid flow. The fractal dimension extracted from the nine coals varies from 1.321-1.584, and the permeability calculated from LBM method varies from 0.147 to $0.345 \mathrm{D}$; in contrast to other studies, a nonmonotonic change, an inverted U-shaped, of permeability on fractal dimension was observed. Moreover, permeability decreases as pressure increases and increases with increasing temperature due to the physical properties of methane and coal matrix. Therefore, this work may contribute to understanding the process of hydrofracturing and hydrothermal methods for improving CBM reservoirs during enhancing CBM recovery.

Keywords: Coal; Micro-fractures morphology; Permeability; Fractal theory; Lattice Boltzmann method

\section{Introduction}

Coalbed methane (CBM) is an essential component of the unconventional energy system due to its huge reserves, the reservoir of which is deemed as a dual-porous medium with pores in matrix and fractures/cleats [1-3]. Pores are generally associated with the processes of gas storage, desorption and diffusion [4]. For fractures, composed by micro-fractures and macrofractures, they are the most important physical attribute governing gas flow in a CBM reservoir $[5,6]$. Generally speaking, natural fractures primarily contributed to the permeability of coal, while the pores in coal matrix have very limited influence on coal permeability [7]. Extensive works including experiments and numerical simulations have been conducted to understand the performance of micro-fracture with the width at micron scale due to its importance on CBM 
production [8-24]. Multiple experimental methods can be used to characterize micro-fractures properties, including low-field nuclear magnetic resonance (NMR) $[8,9]$, X-ray computed micro-tomography (X-ray $\mu \mathrm{CT})$ [10-12] and the classic optical microscopy [13]. NMR is a nondestructive measurement and has been adopted successfully to detect and quantify the porefracture structure of coals [8], where the $\mathrm{T}_{2}$ spectrum larger than $100 \mathrm{~ms}$ represents microfracture [9]. However, the detailed morphological features of micro-fracture are not accessible through NMR. X-ray $\mu \mathrm{CT}$ can provide realistic three-dimensional digital images and different components reconstruction [10-12]. Jenkins et al. [12] utilized X-ray $\mu \mathrm{CT}$ to dynamically measure the deformation behavior of tested rock under various loading conditions. However, $\mathrm{X}$-ray $\mu \mathrm{CT}$ is expensive and time-consuming. Compared with the above techniques, the microfracture morphology observation by optical microscopy is not only economically suitable but also easy to obtain clear morphologies [13]. Besides, the fractal dimension can extend the qualitative description of the micro-fracture network to a quantitative description, which quantifies its complexity of distribution $[14,15]$. The box-counting method $(\mathrm{BCM})$ is one of the most popular algorithms $[16,17]$ to acquire the complexity, namely fractal dimension, through the images of pore-fracture structure. Herein, the BCM will be utilized to quantify the complexity of micro-fractures. On the other hand, direct numerical methods including finite difference method (FDM) [18], finite element method (FEM) [19] and finite volume method (FVM) [20] can be effectively adopted to simulate the flow behavior in micro-fracture networks. But these traditional simulation methods on the basis of Navier-Stokes equations require complicated meshing process to define the simulation domain and are challenging to solve complex geometric boundaries and have low parallel efficiency [18-20]. The lattice Boltzmann 
method (LBM), as a typical mesoscopic method, has a strong advantage in simulating the flow behavior of porous media with irregular boundaries [21, 22]. For example, Wang et al. [23] decomposed the three-dimensional fracture geometry into primary and secondary roughness through wavelet analysis, and investigated the role of the latter in the flow of rock fractures using LBM. And Zhao et al. [24] adopted LBM to discuss the effect of structure, surface roughness and aperture on flow in constructed fracture networks with rough surfaces.

The previous works on coal fractures/cleats can be classified into two parts: characterization of micro-fracture networks [8-13] and the exploration of gas flow behavior in the micro-fracture networks [18-24]. It is significant for understanding the effect of natural fracture network on permeability through investigating the characteristics and distribution of natural fractures in coal. Besides, owing to the complexity of the natural fracture network in coal, much related work has performed flow simulation in the fracture network constructed by algorithms such as Voronoi tessellations method [24, 25] and Fracture Pipe Network Model (FPNM) [26], whereas rare researches have been conducted on the real complex natural fracture networks with specific morphologies. Many studies adopted an idealistic tube model with a circular cross-section to simplify the flow simulation $[27,28]$. However, in most cases, the shape of micro-fractures is non-circular and irregular in coal, which is much complicated. Therefore, Yuan et al. [29] compared the realistic shape with the permeability characteristics of circle, square and equilateral triangular cross-sections, which found that the permeability of the network with circle cross-section is the highest, followed by the realistic shape, and the final are square and equilateral triangular. This finding corroborates the importance of accurately acquiring morphological features in micro-fracture networks. 
In this study, we aim to investigate the flow behavior in natural micro-fractures with various morphologies under different pressures and temperatures. To detailed address the flow behavior in micro-fractures, the specific morphologies of natural micro-fractures were firstly obtained by optical microscopy. And then, the BCM was used to quantify the complexity of the natural micro-fracture network. Finally, the LBM was applied to simulate the flow behavior in the natural micro-fracture network with specific morphologies in coals, and the controlling factors were revealed. This study may provide insights into the flow mechanisms of natural microfracture networks with complex morphologies in unconventional reservoirs.

\section{Methodology and validation}

\subsection{Coal sampling and basic analysis}

Nine coal blocks $\left(30 \times 30 \times 30 \mathrm{~cm}^{3}\right)$ with different coal ranks were selected from the eastern Ordos Basin, north China. The maximum vitrinite reflectance $\left(\mathrm{R}_{\mathrm{o}, \max }\right)$ and maceral composition were carried out with a Leitz MPV-III microscope photometer following the Chinese National Standard of GB/T $6948-1998$. The $\mathrm{R}_{\mathrm{o}, \max }$ varies from $0.62 \%$ to $1.78 \%$ as shown in Table 1 , which may indicate the variable inner micro-fractures existed [30]. Coal macerals were tested by the point counting technique according to the scheme of the International Committee for Coal and Organic Petrology [31]. The coal composition differs, with vitrinite of 65.4-90.2\%, inertinite of 4.5-25.6\%, exinite of $0-5.9 \%$ and mineral being $0.2-8.3 \%$. Natural micro-fractures of coals selectively develop in macerals/submacerals, for example, micro-fractures develop well in the telocollinites while others including the desmocollinite, vitrodetrinite, inertodetrinite and semifusinite are not conducive to micro-fractures development [30].

\subsection{Micro-fractures characterization by optical microscopy}


110 The morphological characteristics of the natural micro-fractures can be clearly observed by

111 optical microscopy. The specific preparation process of used coals is as follows: first a certain

112 proportion of resin and paraffin was melted, and then was poured into the micro-fractures of

113 coal. After that, the coals were cut and polished into the blocks with the area of $\sim 3 \times 3 \mathrm{~cm}^{2}$. To

114 the end, LABORLUX 12 POL optical microscopy (Leitz Company of Germany) was utilized

115 to observe the natural micro-fractures performance including the morphological characteristics.

116 Natural micro-fractures morphologies with the image resolution of $0.4937 \mu \mathrm{m}$ were achieved,

117 which contain various shapes involving dendritic, reticular, filamentous and orthogonal

118 structure as shown in Fig. 1. The natural dendritic micro-fracture network is mostly composed

119 of a backbone and several branches extending out (see Fig. 1a, e, g and h). The natural reticular

120 micro-fracture network can be divided into regular type (Fig. 1b) and disorganized type (Fig.

121 1f), which have the common feature of more than two main channels and the part of branches

122 connecting the main channels, and their difference is whether the channel is curved and

123 disorganized. The natural filamentous micro-fracture network primarily has a channel similar

124 to a ribbon with weak connectivity. Comparatively, the orthogonal micro-fracture network is

125 easy to distinguish, which has a pair of orthogonal channels.

126 After collecting the images, these images need to be preprocessed including noise reduction

127 and image segmentation. First to reduce noise, which normally due to the limitations of the

128 experimental equipment, herein the median filter is chosen to reduce the noise for studied

129 images (Fig. 2). And then the images need to be segmented by Otsu algorithm, which has been

130 proved to be an effective and conciseness threshold segmentation method [16, 32]. After

131 thresholding, the micro-fractures were distinguished from the background in the selected coals. 
132 As shown in Fig. 2c, black is the micro-fracture and white is the coal matrix in the binary

133 images. Detailed observation shows that the noise in the red rectangular frame of Fig. $2 \mathrm{c}$ is

134 significantly less than that in Fig. 2b; what's more the edge of the micro-fracture in Fig. 2c is

135 smoother after noise reduction.

\section{$136 \quad 2.3$ Fractal theory applied for micro-fractures network}

137 The fractal theory proposed by Mandelbrot [33] can be used to evaluate the natural porous

138 properties such as coals and shales. The fractal dimension, the characteristic parameter of fractal

139 theory, can effectively quantify the complexity of pore-fracture structure. For a two-

140 dimensional (2D) system, the fractal dimension changes from 1 to 2 ; a larger the fractal

141 dimension represents a more complicated fracture system. Previous research has been

142 demonstrated that fractal dimensions of pore-fracture structure can be acquired from images by

143 the box-counting method $[16,17,34,35]$. In this study, the fractal dimensions of obtained 2D

144 micro-fracture images were determined by the BCM to quantify the complexity of the micro-

145 fracture distribution. The details of BCM have been listed in our latest work [35], and the

146 following is a brief description:

147 By covering a binary image with boxes of length $r$, the fractal dimension $D$ can be estimated

148 as:

149

$D=-\lim _{r \rightarrow 0} \frac{\log (N(r))}{\log (r)}$

150 where $N(r)$ is the number of boxes required to cover the complete image. The side length $r$

151 of the box needs to be assigned a series of values, and the number of boxes $N(r)$ required to

152 cover the image is counted. Then a set of $[\log (r), \log (\mathrm{N}(r))]$ values of each sample are plotted

153 in the coordinate system with the abscissa of $\log (r)$ and the ordinate of $\log (\mathrm{N}(r))$. The slope is 
$169 \tau=\frac{v}{c_{s}^{2} \delta_{t}}+\frac{1}{2}$

170 where $v$ is the kinematic viscosity; $c_{s}=\sqrt{R T}=c / \sqrt{3}$ is the sound speed, in which $R$ is

171 the gas constant and $T$ is the temperature. The DnQb model ( $\mathrm{n}$ is the spatial dimension and $\mathrm{b}$ is the number of discrete velocity vectors) proposed by Qian et al. [38] is the most representative. We utilize the D2Q9 model (see Fig.

$1742 \mathrm{~d}$ ), and its equilibrium distribution function $f_{i}^{(e q)}$ can be expressed as: 
176 where $c=\delta_{x} / \delta_{t}$ is the lattice velocity, and both the lattice size $\delta_{x}$ and time step $\delta_{t}$ are

177 set to 1 . The $\boldsymbol{e}_{i}$ and weight coefficient $\omega_{i}$ are defined as:

$\boldsymbol{e}_{i}=c\left[\begin{array}{lllllllll}0 & 1 & 0 & -1 & 0 & 1 & -1 & -1 & 1 \\ 0 & 0 & 1 & 0 & -1 & 1 & 1 & -1 & -1\end{array}\right]$

$i=0,1, \ldots, 8$

179

$\omega_{i}= \begin{cases}4 / 9 & i=0 \\ 1 / 9 & i=1-4 \\ 1 / 36 & i=5-8\end{cases}$

180 For isothermal gas flow, the macroscopic parameters, such as density and momentum, can be

181 determined as:

$182 \rho=\sum_{i} f_{i}, \rho \boldsymbol{u}=\sum_{i} \boldsymbol{e}_{i} f_{i}$

183 The pressure boundary conditions are applied to the inlet and outlet. The stationary non-slip

184 boundary is drawn on the solid wall. We default the simulation to reach a steady state when the

185 velocity change of each grid between two time steps is less than $0.0001 \%$. Note that the fact

186 that the isothermal boundary condition has been adopted in the above deduction.

187 The lattice units are used in the above-mentioned parameters. Therefore, it is necessary to

188 convert the studied physical quantity (e.g. permeability) from the lattice unit to the physical

189 unit. The permeability can be determined by Eq. (8) following the theoretical model of capillary

190 model.

$191 \frac{K}{K_{L B M}}=\left(\frac{L}{L_{L B M}}\right)^{2}$

192 where $K$ and $K_{L B M}$ are the intrinsic permeability with physical unit and the permeability

193 simulated by LBM, respectively. $L$ is the real scale of coal sample and $L_{L B M}$ is the scale of LBM. 
194 Other physical property parameters such as kinematic viscosity required for methane under

195 different pressure and temperature conditions can be obtained from the open source software

196 called Peace software.

\subsection{Validation of Box-counting and lattice Boltzmann methods}

\subsubsection{Box-counting method}

199

200

201

202

203

204

Sierpinski Carpet as a classic figure (as shown in Fig. 3a) in fractal theory can be used to verify the accuracy of our calculation program. The definition of fractal dimension determines Sierpinski Carpet's theoretical fractal dimension $D=\frac{\ln 8}{\ln 3} \approx 1.8928$. As presented in Fig. 3b, the actual result we calculated is also 1.8928 , which indicates that the actual result is in good agreement with the theoretical value. In other words, this comparison confirms that our program is feasible.

\subsubsection{Lattice Boltzmann method}

The second validation is carried out by simulating the flow of two-dimensional Poiseuille with different lattice sizes including $100 \times 100,250 \times 250$ and $500 \times 500$. The normalized streamwise velocity profiles $U=u / u_{\max }$ are compared with the analytical solution as shown in Fig. 4, which shows that the simulation results based on a series of lattice sizes are highly consistent with the analytical solutions. This consistency also confirms that the LBM is suitable for understanding the flow capability.

\section{Results and discussion}

Micro-fracture morphology, pressure and temperature are three of the important factors affecting permeability and thus enhancing CBM recovery [39-41]. This section captured the flow characteristics of methane under different micro-fractures morphologies, different 
pressures and temperatures based on the $\mathrm{D} 2 \mathrm{Q} 9$ model. The pressure gradient was set to 0.1

$\mathrm{MPa} / \mathrm{m}$ in the simulation along the flow direction.

\subsection{Effects of micro-fracture morphology on flow capability}

The pre-existing natural fractures characteristics are of importance on the hydraulic fracturing stimulation effect [7]. Herein, the effect of pre-existing natural fracture morphology on methane flow in coal will be discussed in detail. The velocity distribution results with different microfractures morphologies are displayed in Fig. 5 as the simulation reaches steady state (i.e. the velocity change of each grid between two time steps is less than $0.0001 \%$ ). Fig. 5 demonstrates that the pressure-driven methane migration in various micro-fracture networks is different. It is easy to find out that the existence of dominant channels is conducive to the gas flow, that is, there is a wide channel connecting the inlet to the outlet in the micro-fracture network as shown in Fig. 1.The length and width of the dominant channel was listed in Table 2, which has the average length and width of $\sim 498.26 \mu \mathrm{m}$ and $10.96 \mu \mathrm{m}$, respectively. The velocity in the dominant channel is much larger compared with other locations (see Fig. 5). As shown in Fig. channels with width less than $5 \mu \mathrm{m}$. Another interesting phenomenon is that the special microfracture morphology determines the time that the flow simulation reaches the steady state, which varies from 5711 to 130561 showing greatly different. This result means that the time

234 for the simpler micro-fracture network is much shorter to reach the steady state, while the micro-fracture network with a more special shape (e.g., the orthogonal type in Fig. 5i and Fig. 6) and a more complex distribution (see Fig. 5g) takes longer to reach steady state. The equilibrium time in Fig. 5 is used as the standard to evaluate the difficulty of fluid flow in 
micro-fracture network, the orthogonal micro-fracture is unfavorable for flow capability, and the most favorable network is reticular. And the dendritic and filamentous types are in between the orthogonal and reticular types. The dendritic type with more branches will cause obstacles to flow. The filamentous type has a lot of narrow throats, which result in flow in filamentous structure more difficult than that in the dendritic structure with fewer branches. Fig. 6 displays the simulated flow process of the orthogonal micro-fracture network. At the beginning of the flow process, the gas will extend in three directions after meeting the bifurcation. As time goes on, the gas will flow further following with the branches. At this time, the upward and downward flow directions do not match the main flow direction; therefore, the gas in the up and down directions will gradually disappear. When the simulation reaches the steady state, the gas only passes in the main flow direction. The computation time also becomes longer due to the special angle (e.g., orthogonal type) of the branches in the natural micro-fracture network. The fracture dimension values calculated by BCM are displayed in Fig. 7, which ranges from 1.321 to 1.584 . The larger the value is, the more complicated distribution of the natural microfracture network [16]. Besides, Fig. $8 \mathrm{~b}$ reveals that there is an obvious positive correlation between the fractal dimension and the fracture porosity. This phenomenon may be ascribed to two causes: the first is that micro-fracture network with lager fracture porosity will have a greater chance of being more complicated distribution, which is consistent with Wu et al. [36]. Secondly, the micro-fracture network filled with minerals is poor developed, thus there is no complex trend that is similar to the relationship between porosity and fractal dimension [35]. As shown in Fig. 8a, there is a significant inverted U-shaped relationship between fractal dimension and permeability with the correlation coefficient of 0.86 . The permeability increases 
as fractal dimension increases from 1.321 to 1.472 , and then decreases as fractal dimension exceeds 1.472 . The permeability is $0.147 \mathrm{D}$ when the fractal dimension is 1.321 , while it increases to $0.345 \mathrm{D}$ as fractal dimension reaches to 1.472 . The reason for this increasing trend is that lower fractal dimension normally corresponds to lower fracture porosity, resulting in lower permeability. As the fractal dimension increases, the fracture porosity also increases, and the permeability is improved when the connectivity of the micro-fracture network is good. However, when the fractal dimension exceeds 1.472, the micro-fracture network becomes more complex. Meanwhile, due to the strong heterogeneity of the CBM reservoir and poor connectivity $[1,26,42]$, the natural micro-fracture network is connected by the narrow throat, leading to difficult gas flow and thus lower permeability. Fig. 9 shows that the methane still flows through the micro-fracture network branch $\mathrm{f} 1$ (see f2) at the beginning of the flow process, but methane will not pass through these channels as time increases. Hence, under the premise of only one flow direction, the flow time will undoubtedly take longer if many branches exist in the micro-fracture network. And if the extension direction of these branches is different from the flow direction, it would constrain the permeability.

\subsection{Effects of pressure on flow capability}

The trend of permeability together with outlet pressure is shown in Fig. 10, which illustrates that the permeability decreases sharply as pressure increases from $0.1 \mathrm{MPa}$ to $5 \mathrm{MPa}$, and then the permeability tends to be stable as pressure exceeds $5 \mathrm{MPa}$. In other words, the natural microfracture network is more sensitive to change in permeability at low pressure because the distance between the rarefied gas molecules is far away and the attractive force is weak at low pressure [29]. The decreasing trend of permeability with increasing pressure is consistent with 

is no similar trend in CBM production by Shi and Durucan [44]. During the CBM production,

284 the permeability initially declines and then increases with increasing pressure $[6,44]$. The reason for this phenomenon is that the shrinkage of the coal matrix due to gas desorption, a unique characteristic of coal reservoir, counteracts the permeability decrease with pressure drop during the production $[4,45]$. Therefore, a model considering matrix swelling/shrinkage can accurately describe actual flow characteristics. Due to its extremely challenging nature, coal matrix swelling/shrinkage response during gas flow should be considered into the permeability model.

\subsection{Effects of temperature on flow capability}

Three sets of temperatures were simulated to study the effects of temperature changes including 300K, $330 \mathrm{~K}$ and $360 \mathrm{~K}$ on coal permeability. Fig. 10 exhibits that the permeability increase with increasing temperature at the constant pressure. The increase of temperature will aggravate the thermal motion of gas molecules, leading to the average kinetic energy of the molecules increasing and thereby increasing the permeability, which is in accordance with previous research [29]. And at low pressure, the influence of temperature on permeability is more sensitive. For realistic CBM production, the effect of temperature on coal permeability is related to many factors, such as coal rank and pore-fracture structure [39, 42]. For instance, Cai et al.

300 [39] revealed that different rank coals have different trends in permeability changes caused by temperature. And Liu et al. [42] found that the temperature has obvious impact on the mechanical properties and acoustic emission characteristics in coal, and the pore-fracture structures were promoted and the permeability was significantly improved under temperature 
treatment. CBM reservoirs normally have the characteristics of complex pore-fracture structure, strong heterogeneity, and abundant mineral types, which cause a series of physical and chemical changes in the process of temperature increase [46]. Different components in coal have different shrinking and swelling ability under the effect of temperature [42]. For example, the temperature stress will aggravate the expansion of fractures and weaken the mechanical properties of coal [42]. Moreover, during the exploitation of CBM, the reservoir temperature also changes dynamically with produced gases; thus, the effect of temperature on permeability should be cautiously considered [47]. Therefore, the micro-fracture morphology, pressure and temperature have a comprehensive complex influence on gas flow capability, which generally follows the dominated micro-fracture morphology, supplemented by pressure and temperature as shown in Fig. 11.

Although the detailed work on the morphology effect of micro-fracture network on permeability has been revealed, the process of fluid-solid coupling has yet to confirm.

Therefore, the flow response in micro-nano scale natural pore-fracture structure during the CBM development will be our next work.

\section{Conclusions}

In this study, natural micro-fracture morphologies of selected Chinese coals from the Ordos Basin were characterized by the optical microscope. And the box-counting method together with the lattice Boltzmann method was adopted to quantify the complexity of the micro-fracture network and flow behaviors in these natural micro-fracture networks. Besides, factors affecting the flow capability in these natural micro-fracture networks were discussed. The following conclusions can be made: 
326 1) The dominant channels in the natural micro-fracture network will greatly improve the 327 permeability. Besides, flow characteristics in the micro-fracture networks with various 328 morphologies are quite different, which presents that the orthogonal type is unfavorable for 329 flow capability, and the most favorable network is reticular, with dendritic and filamentous 330 types in between.

331 2) An obvious inverted U-shaped relationship exists between the fractal dimension and 332 permeability. When the fractal dimension is lower than 1.472 , the larger fractal dimension 333 means the greater fracture porosity, and thus the permeability of well-connected natural micro334 fractures increase. As the fractal dimension exceeds 1.472 , the distribution of natural micro335 fracture network is complicated, which presents reticular and dendritic types. And the 336 connected narrow throats normally lead to a permeability decrease.

337 3) Pressure and temperature have opposite influence on coal permeability. The permeability 338 increases with decreasing gas pressure, which is caused by the rarefied gas due to the declining 339 pressure. However, the gas at high temperatures of $360 \mathrm{~K}$ will lead to a gentle increase of 340 permeability.

\section{Acknowledgements}

342 This research was funded by the National Natural Science Foundation of China (grant nos. 34341830427,41922016 and 41772160) and the Fundamental Research Funds for Central 344 Universities (grant no. 2652019255). The authors also want to thank the Royal Society Edinburgh 345 and NSFC to support their collaborations.

\section{References}

347 [1] Moore TA. Coalbed methane: A review. Int J Coal Geol 2012;101:36-81.

348 [2] Vishal V, Singh TN, Ranjith PG. Influence of sorption time in CO2-ECBM process in 
Indian coals using coupled numerical simulation. Fuel 2015;139:51-8.

350 [3] Jia D, Qiu YK, Li C, Cai YD. Propagation of pressure drop in coalbed methane reservoir during drainage stage. Advances in Geo-Energy Research 2019;3(4):387-95.

[4] Cai YD, Li Q, Liu DM, Zhou YF, Lv DW. Insights into matrix compressibility of coals

[5] Laubach SE, Marrett RA, Olson JE, Scott AR. Characteristics and origins of coal cleat:

[6] Pan ZJ, Connell LD. Modelling permeability for coal reservoirs: A review of analytical

[7] Yao WL, Mostafa S, Yang Z, Xu G. Role of natural fractures characteristics on the

[8] Zheng SJ, Yao YB, Liu DM, Cai YD, Liu Y. Nuclear magnetic resonance surface relaxivity of coals. Int J Coal Geol 2019;205:1-13.

[9] Harmer J, Callcott T, Maeder M, Smith BE. A novel approach for coal characterization by NMR spectroscopy: global analysis of proton $\mathrm{T} 1$ and $\mathrm{T} 2$ relaxations. Fuel 2001;80(3):417-25.

[10] Mathews JP, Campbell QP, Xu H, Halleck P. A review of the application of X-ray computed tomography to the study of coal. Fuel 2017;209:10-24.

[11] Balucan RD, Turner LG, Steel KM. X-ray mu CT investigations of the effects of cleat demineralization by $\mathrm{HCl}$ acidizing on coal permeability. J Nat Gas Sci Eng 2018;55:206-18.

[12] Jenkins DR, Lomas H, Mahoney M. Uniaxial compression of metallurgical coke samples with progressive loading. Fuel 2018;226:163-71.

[13] Cai YD, Liu DM, Pan ZJ, Che Y, Liu ZH. Investigating the effects of seepage-pores and fractures on coal permeability by fractal analysis. Transport Porous Med 2016;111(2):479-97.

[14] Mahnke M, Mögel HJ. Fractal analysis of physical adsorption on material surfaces. Colloids and Surfaces A: Physicochemical and Engineering Aspects 2003;216(13):215-28.

[15] Peng C, Zou CC, Yang YQ, Zhang GH, Wang WW. Fractal analysis of high rank coal from southeast Qinshui basin by using gas adsorption and mercury porosimetry. J Petrol Sci Eng 2017;156:235-49.

[16] Liu XF, Nie BS. Fractal characteristics of coal samples utilizing image analysis and gas adsorption. Fuel 2016;182:314-22.

[17] Lopes R, Betrouni N. Fractal and multifractal analysis: A review. Medical Image Analysis 2009;13(4):634-49.

[18] Liu P, Qin YP, Liu SM, Hao YJ. Modeling of gas flow in coal using a modified dualporosity model: a multi-mechanistic approach and finite difference method. Rock Mechanics and Rock Engineering 2018;51(9):2863-80.

[19] Sun Z, Loge RE, Bernacki M. 3D finite element model of semi-solid permeability in an equiaxed granular structure. Computational Materials Science 2010;49(1):158-70.

[20] Almasoodi M, Reza Z. Finite-volume computations of shale tortuosity and 
[21] Aidun CK, Clausen JR. Lattice-Boltzmann method for complex flows. Annual Review

[22] Liu HH, Kang QJ, Leonardi CR, Schmieschek S, Narvaez A, Jones BD, et al. Multiphase lattice Boltzmann simulations for porous media applications. Computational Geosciences 2016;20(4):777-805.

[23] Wang M, Chen YF, Ma GW, Zhou JQ, Zhou CB. Influence of surface roughness on nonlinear flow behaviors in 3D self-affine rough fractures: Lattice Boltzmann simulations. Adv Water Resour 2016;96:373-88.

[24] Zhao YL, Wang ZM, Ye JP, Sun HS, Gu JY. Lattice Boltzmann simulation of gas flow and permeability prediction in coal fracture networks. J Nat Gas Sci Eng 2018;53:15362.

[25] Zhao YL, Wang ZM, Qin X, Li JT, Yang H. Stress-dependent permeability of coal fracture networks: A numerical study with Lattice Boltzmann method. J Petrol Sci Eng 2019;173:1053-64.

[26] Jing Y, Armstrong RT, Mostaghimi P. Image-based fracture pipe network modelling for prediction of coal permeability. Fuel 2020;270.

[27] Wang JJ, Kang QJ, Chen L, Rahman SS. Pore-scale lattice Boltzmann simulation of micro-gaseous flow considering surface diffusion effect. Int J Coal Geol 2017;169:6273.

[28] Gupta N, Fathi E, Belyadi F. Effects of nano-pore wall confinements on rarefied gas dynamics in organic rich shale reservoirs. Fuel 2018;220:120-9.

[29] Yuan YD, Wang YZ, Rahman SS. Reconstruction of porous structure and simulation of non-continuum flow in shale matrix. J Nat Gas Sci Eng 2017;46:387-97.

[30] Yao YB, Liu DM. Microscopic characteristics of microfractures in coals: an investigation into permeability of coal. Procedia Earth and Planetary Science 2009;1(1):903-10.

[31] International Committee for Coal and Organic Petrology (ICCP). The new vitrinite classifcation (ICCP System 1994). Fuel 1998;77(5):349-58.

[32] Zhou HW, Xie H. Direct estimation of the fractal dimensions of a fracture surface of rock. Surf Rev Lett 2003;10(5):751-62.

[33] Mandelbrot BB. The fractal geometry of nature. Sciences 1983;23(5):63-8.

[34] Ai T, Zhang R, Zhou HW, Pei JL. Box-counting methods to directly estimate the fractal dimension of a rock surface. Appl Surf Sci 2014;314:610-21.

[35] Li Q, Liu DM, Cai YD, Zhao B, Qiu YK, Zhou YF. Scale-span pore structure heterogeneity of high volatile bituminous coal and anthracite by FIB-SEM and X-ray $\mu$-CT. J Nat Gas Sci Eng 2020;81:103443.

[36] Wu H, Zhou YF, Yao YB, Wu KJ. Imaged based fractal characterization of microfracture structure in coal. Fuel 2019;239:53-62.

[37] Bhatnagar PL, Gross EP, Krook M. A model for collision processes in gases. i. small amplitude processes in charged and neutral one-component systems. Physical Review 1954;94(3):511-25.

[38] Qian YH, D'Humières D, Lallemand P. Lattice BGK models for Navier-Stokes 
equation. Europhysics Letters (EPL) 1992;17(6):479-84.

[39] Cai YD, Pan ZJ, Liu DM, Zheng GQ, Tang SH, Connell LD, et al. Effects of pressure and temperature on gas diffusion and flow for primary and enhanced coalbed methane recovery. Energ Explor Exploit 2014;32(4):601-19.

[40] Wang G, Han DY, Jiang CH, Zhang ZY. Seepage characteristics of fracture and deadend pore structure in coal at micro- and meso-scales. Fuel 2020;266.

[41] Mostaghimi P, Armstrong RT, Gerami A, Hu YB, Jing Y, Kamali F, et al. Cleat-scale characterisation of coal: An overview. J Nat Gas Sci Eng 2017;39:143-60.

[42] Liu SM, Li XL, Wang DK, Wu MY, Yin GZ, Li MH. Mechanical and acoustic emission characteristics of coal at temperature impact. Natural Resources Research 2020;29(3):1755-72.

[43] Cui G, Liu J, Wei M, Shi R, Elsworth D. Why shale permeability changes under variable effective stresses: New insights. Fuel 2018;213:55-71.

[44] Shi JQ, Durucan S. Exponential growth in San Juan Basin Fruitland coalbed permeability with reservoir drawdown: Model match and new insights. Spe Reserv Eval Eng 2010;13(6):914-25.

[45] Gray I. Reservoir engineering in coal seams: part 1-The physical process of gas storage and movement in coal seams. SPE-12514-PA 1987;2(01):28-34.

[46] Sharma A, Kyotani T, Tomita A. Quantitative evaluation of structural transformations in raw coals on heat-treatment using HRTEM technique. Fuel 2001;80(10):1467-73.

[47] Liu SY, Wei CH, Zhu WC, Zhang M. Temperature- and pressure-dependent gas diffusion in coal particles: Numerical model and experiments. Fuel 2020;266. 


\section{Captions for Figures and Tables}

461 Fig. 1. Different micro-fracture morphologies of selected samples obtained by optical

462 microscope, which varied involving dendritic, reticular, filamentous and orthogonal etc. The

463 red dotted lines are the dominant channels mentioned in section 4.1.

464 Fig. 2. The results after threshold segmentation and the discrete velocity of D2Q9 model. (a) is

465 the initial image; (b) and (c) are images before and after noise reduction, respectively. Careful

466 observation shows that the noise in the red rectangular frame of (c) is significantly less than

467 that in (b), and the edge of the micro-fracture in (c) is smoother after noise reduction. (d) is the 468 discrete velocity of D2Q9 model.

469 Fig. 3. The verification of the box-counting method. (a) is the Sierpinski Carpet image and (b)

470 is the value estimated by the box-counting method.

471 Fig. 4. Normalized streamwise velocity profiles with different lattice sizes.

472 Fig. 5. The velocity distribution results of dimensionless lattice unit when the simulation

473 reaches equilibrium with different micro-fractures morphologies and the schematic diagram of

474 the gas flow model. $t$ is the time for the simulation to reach convergence. (a)- (i) are the velocity

475 distribution results and $(\mathrm{j})$ is the schematic diagram of the gas flow model. Simulation

476 conditions include $\mathrm{T}=300 \mathrm{~K}$, outlet pressure $=10 \mathrm{MPa}$ and pressure gradient $=0.1 \mathrm{MPa} / \mathrm{m}$.

477 Fig. 6. Velocity distribution of sample F9 under different time steps. $t$ is the time step. The

478 length of the arrow indicates how far the gas flows. At the beginning of the flow process, the

479 gas will extend in three directions after meeting the bifurcation. As time goes on, the gas will

480 flow further following with the branches. At this time, the upward and downward flow

481 directions do not match the main flow direction, so the gas in the up and down directions will 
gradually disappear. When the simulation reaches equilibrium, the gas only passes in the main flow direction. The equilibrium time also becomes longer due to the special angle (orthogonal type) of the branches of the microfracture network. Simulation conditions include $\mathrm{T}=300 \mathrm{~K}$, outlet pressure $=10 \mathrm{MPa}$ and pressure gradient $=0.1 \mathrm{MPa} / \mathrm{m}$.

Fig. 7. Results of fractal dimension calculated by the box-counting method

Fig. 8. Relations between permeability, fracture porosity and fractal dimension. (a) fractal dimension versus permeability and (b) fractal dimension versus fracture porosity. $\mathrm{T}=300 \mathrm{~K}$, outlet pressure $=10 \mathrm{MPa}$ and pressure gradient $=0.1 \mathrm{MPa} / \mathrm{m}$.

Fig. 9. Velocity distribution of sample F7 under different time steps. $t$ is the time step. (a) is the initial image of F7 and (b)-(e) are the velocity distribution under different time steps during simulation. $\mathrm{f} 1$ and $\mathrm{f} 2$ are the original image of the branch and the changes that occurred in the branch during the flow process, respectively.

Fig. 10. Relations between pressure, temperature and permeability in different samples. Pressure gradient $=0.1 \mathrm{MPa} / \mathrm{m}$.

Fig. 11. Diagram of the influence mechanism of different factors on permeability, including the micro-fracture morphology, pressure and temperature. The positive and negative signs (“+” and “-”) in the figure represent the promotion and inhibition effects, respectively.

Table 1 Sample information and basic parameters of the selected coals.

Table 2 Statistics of the length and width of the dominant channel of micro-fractures in Fig. 1. 

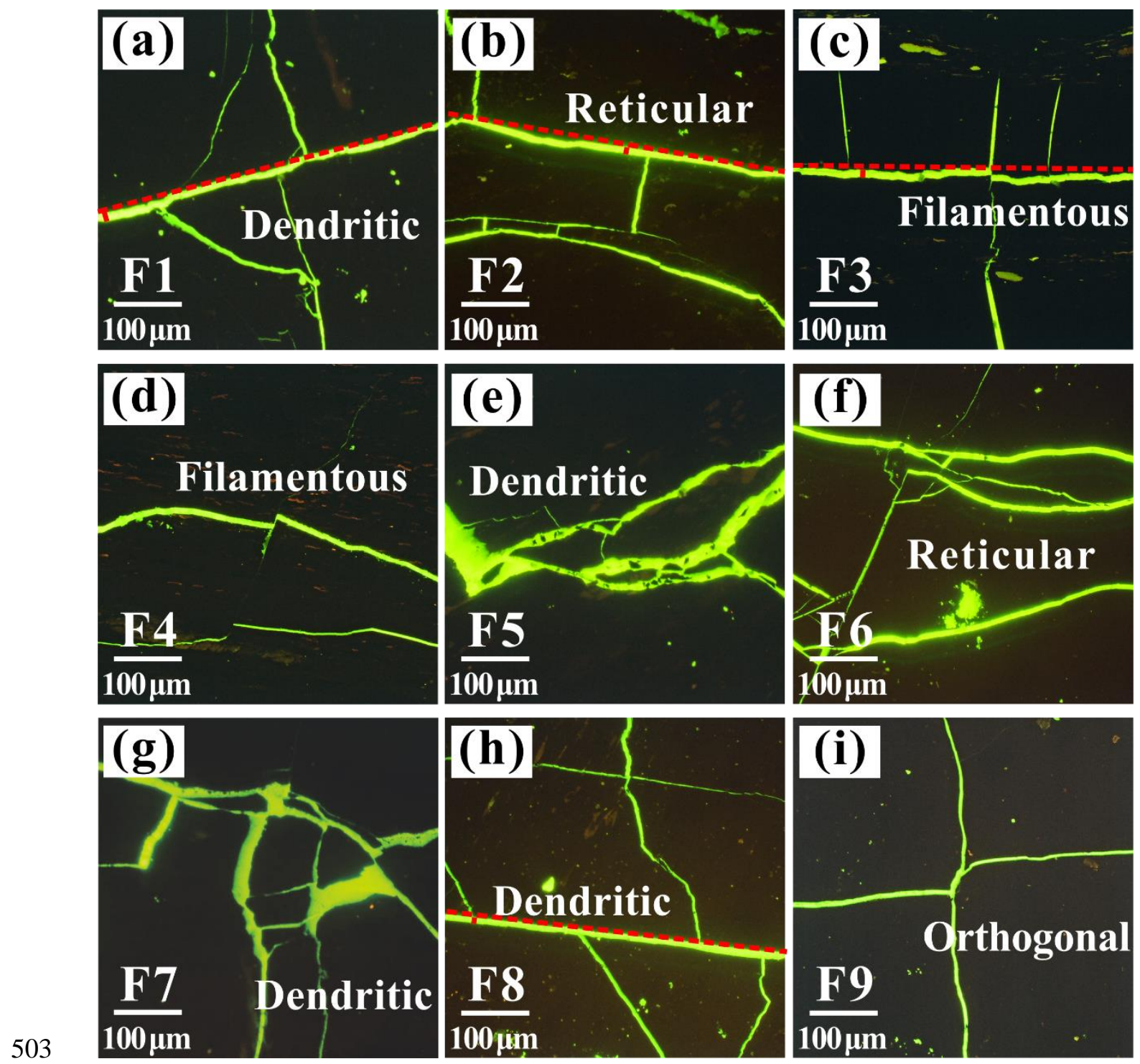

504

Fig. 1. Different micro-fracture morphologies of selected samples obtained by optical microscope,

505 which varied involving dendritic, reticular, filamentous and orthogonal etc. The red dotted lines are the dominant channels mentioned in section 3.1. 

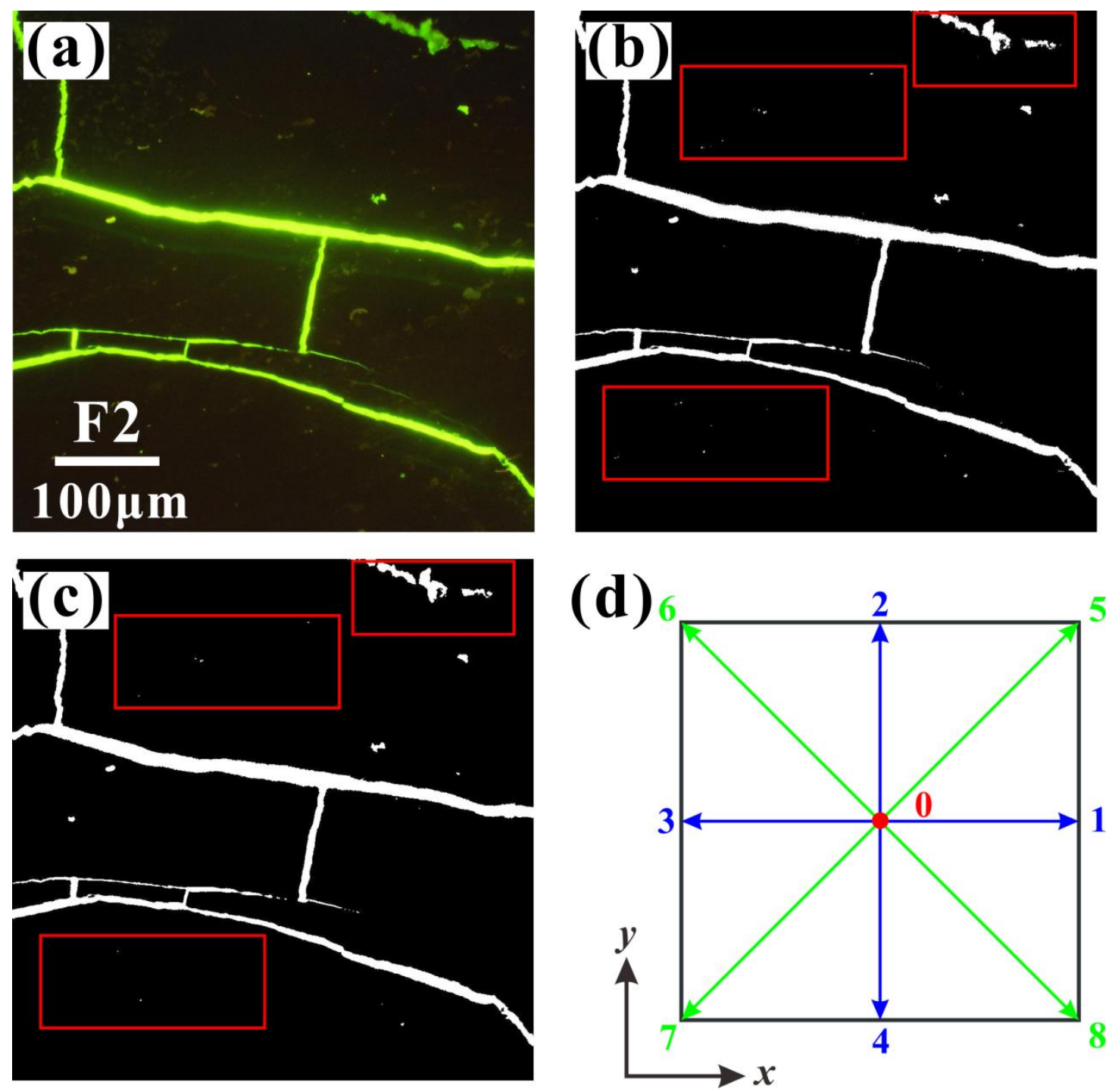

Fig. 2. The results after threshold segmentation and the discrete velocity of D2Q9 model. (a) is the initial image; (b) and (c) are images before and after noise reduction, respectively. Careful

511 observation shows that the noise in the red rectangular frame of (c) is significantly less than that in

512 (b), and the edge of the micro-fracture in (c) is smoother after noise reduction. (d) is the discrete 513 velocity of D2Q9 model. 


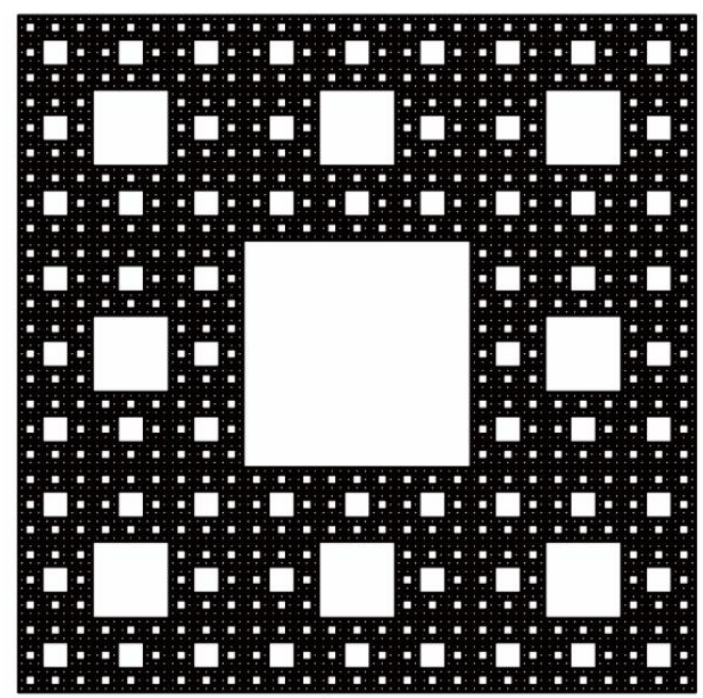

(a)

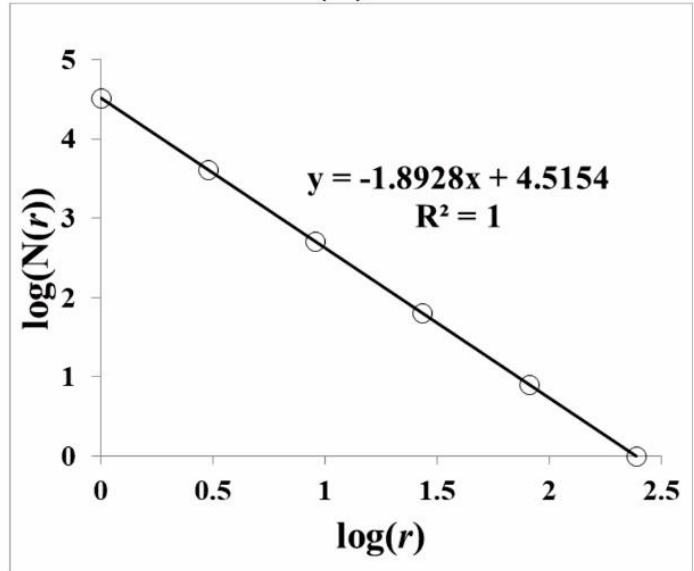

(b)

Fig. 3. The verification of the box-counting method. (a) is the Sierpinski Carpet image and (b) is the value estimated by the box-counting method. 


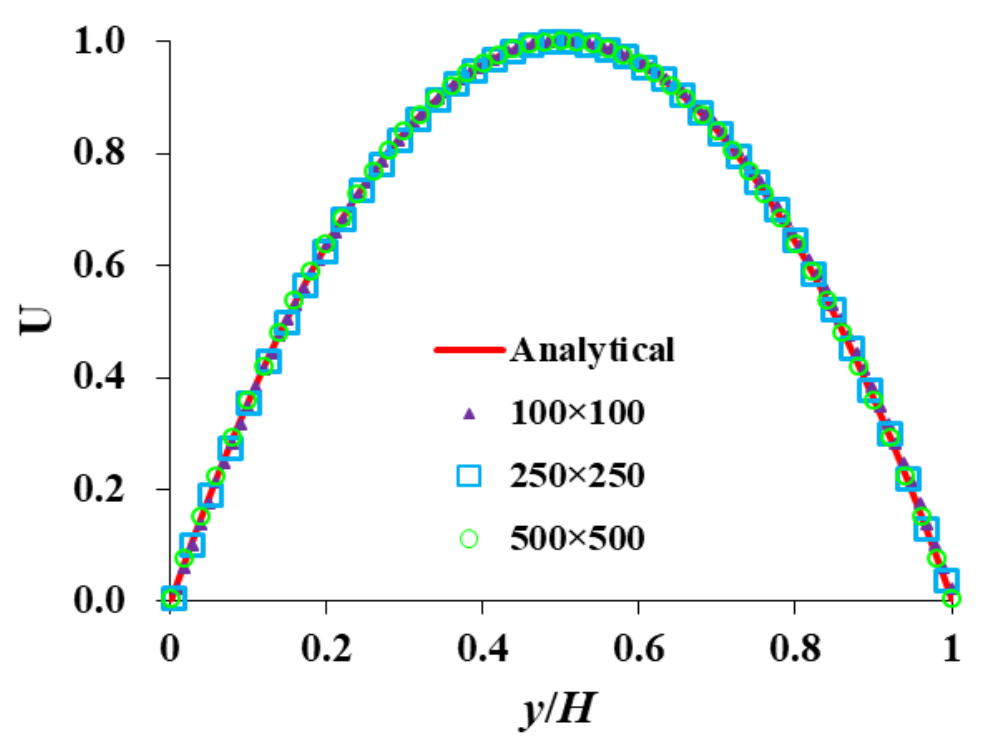

518

519 Fig. 4. Normalized streamwise velocity profiles with different lattice sizes.

520 

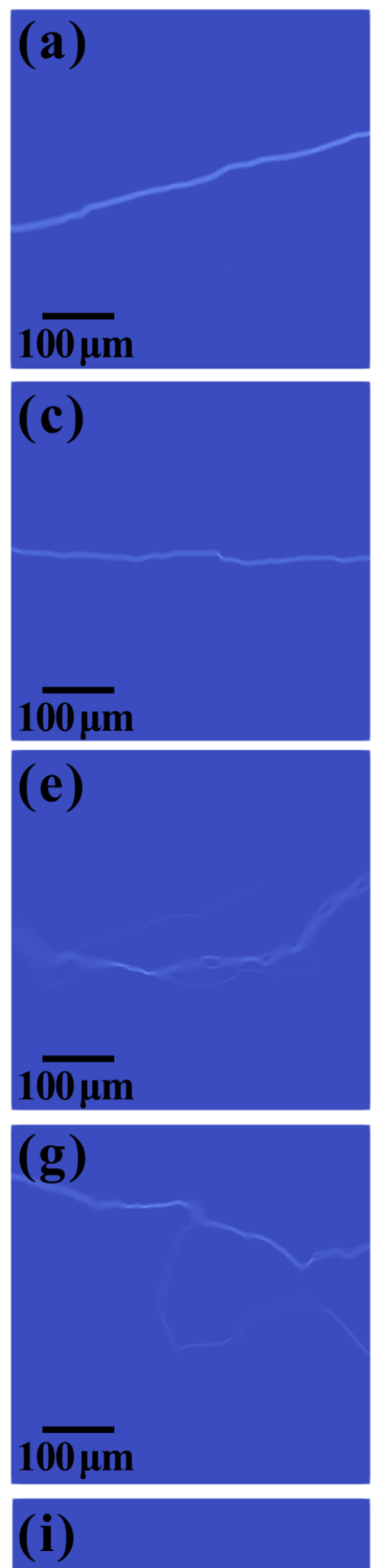

\section{$100 \mu \mathrm{m}$}
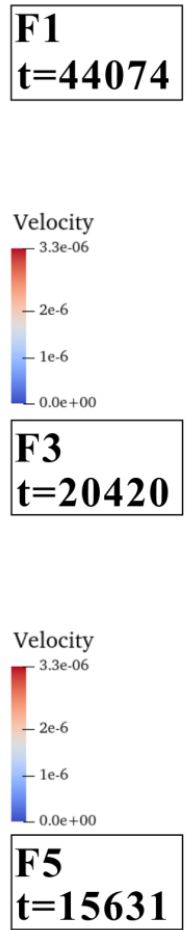

Velocity
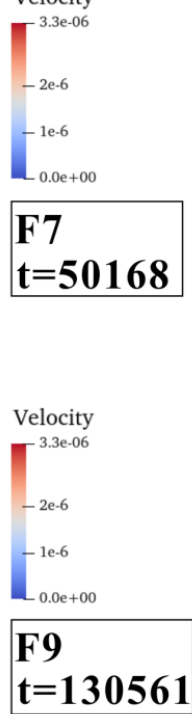

Velocity

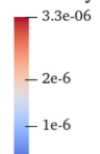

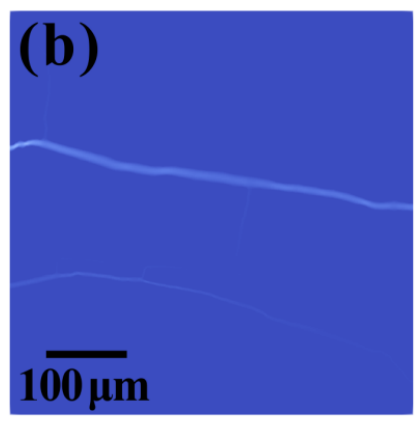

F2

$t=5711$

Velocity

$\tau^{3.3 e-06}$

$-2 \mathrm{e}-6$

-1 e-6

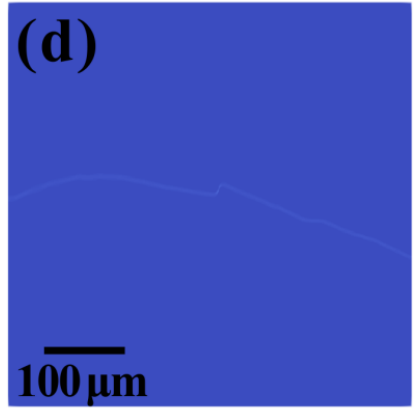

F4

$t=11730$

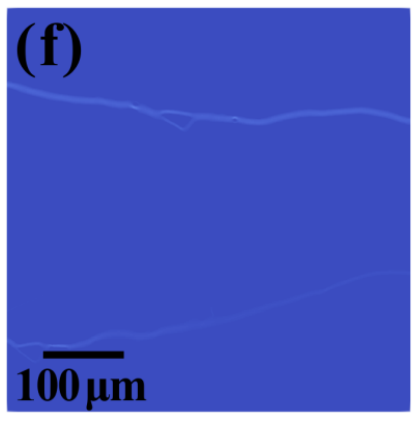

Velocity

$T^{3.3 \mathrm{e}-06}$

$-2 e-6$

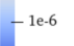

$-0.0 \mathrm{e}+00$

F6

$t=7999$

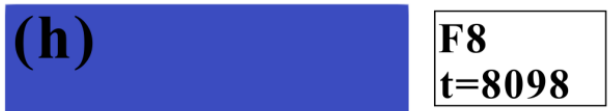

$100 \mu \mathrm{m}$
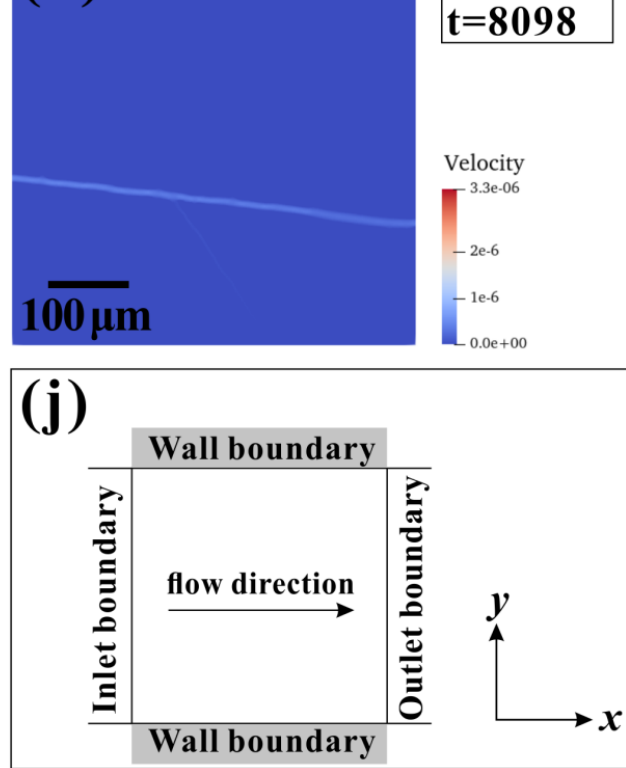

- $0.0 e+00$

Fig. 5. The velocity distribution results of dimensionless lattice unit when the simulation reaches equilibrium with different micro-fractures morphologies and the schematic diagram of the gas flow model. $t$ is the time for the simulation to reach convergence. (a)- (i) are the velocity distribution results and ( $\mathrm{j}$ ) is the schematic diagram of the gas flow model. Simulation conditions include $\mathrm{T}=$ $300 \mathrm{~K}$, outlet pressure $=10 \mathrm{MPa}$ and pressure gradient $=0.1 \mathrm{MPa} / \mathrm{m}$. 

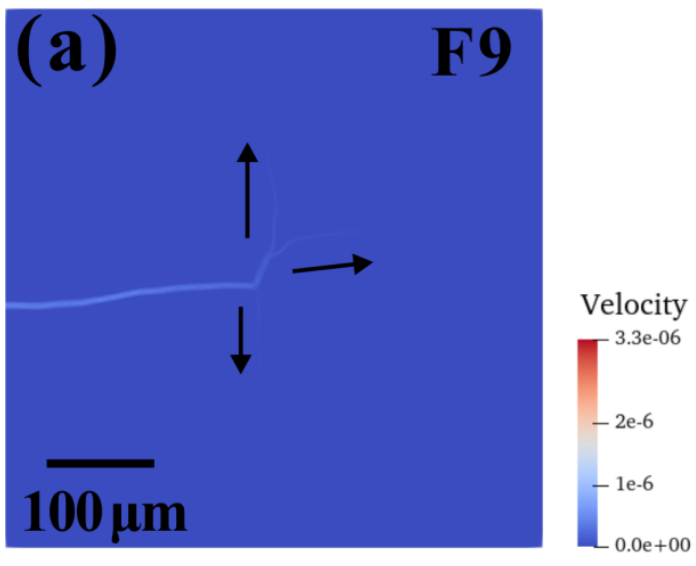

$\mathbf{t}=\mathbf{2 0 0 0}$

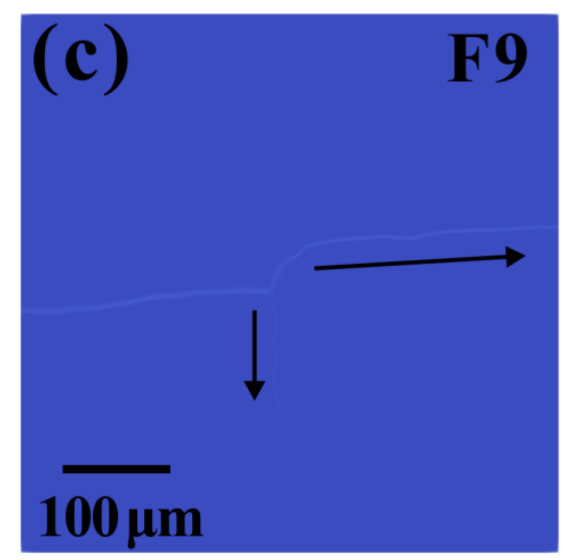

$\mathbf{t}=\mathbf{3 2 0 0 0}$

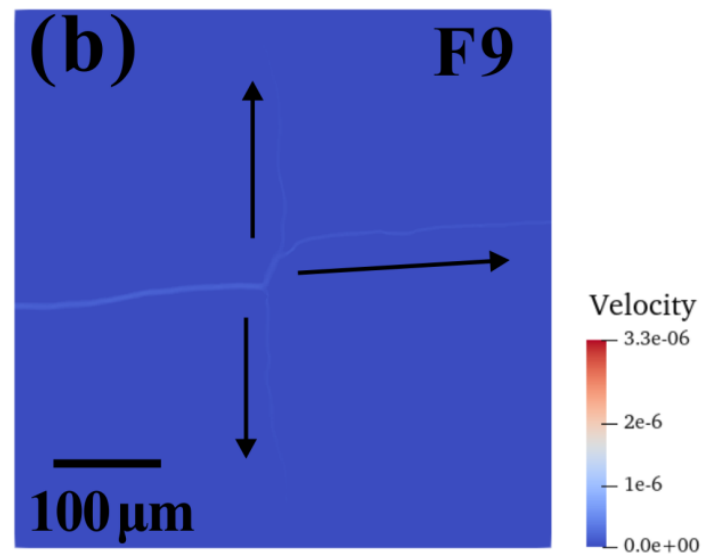

$\mathbf{t}=12000$

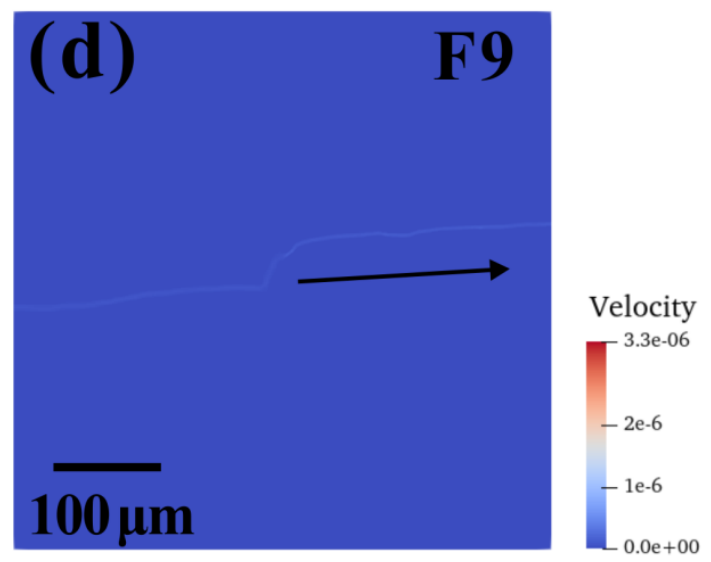

$\mathbf{t}=\mathbf{1 3 0 5 6 1}$

\section{flow direction}

Fig. 6. Velocity distribution of sample F9 under different time steps. $t$ is the time step. The length

of the arrow indicates how far the gas flows. At the beginning of the flow process, the gas will

extend in three directions after meeting the bifurcation. As time goes on, the gas will flow further

following with the branches. At this time, the upward and downward flow directions do not match

the main flow direction, so the gas in the up and down directions will gradually disappear. When 

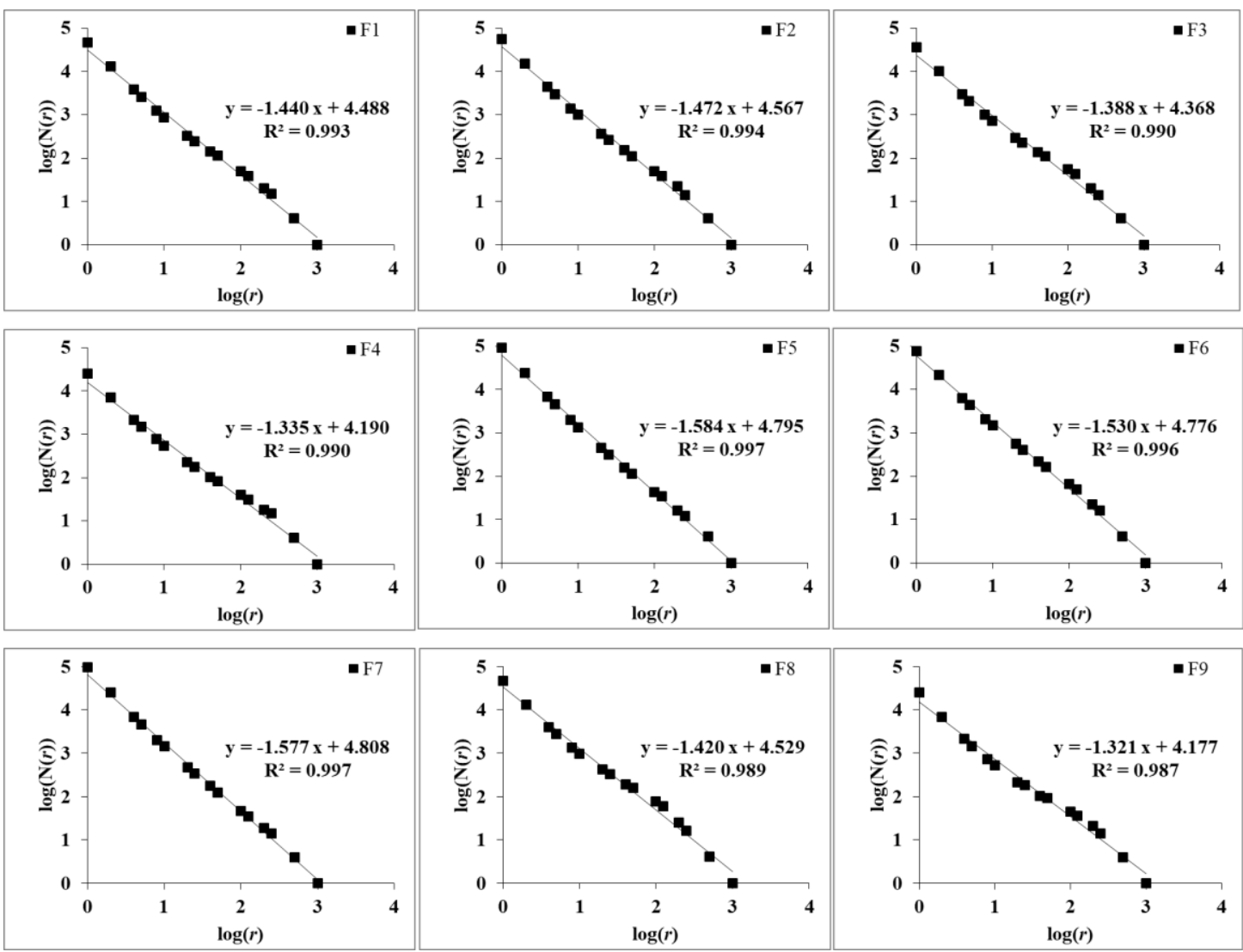

Fig. 7. Results of fractal dimension calculated by the box-counting method 
(a)

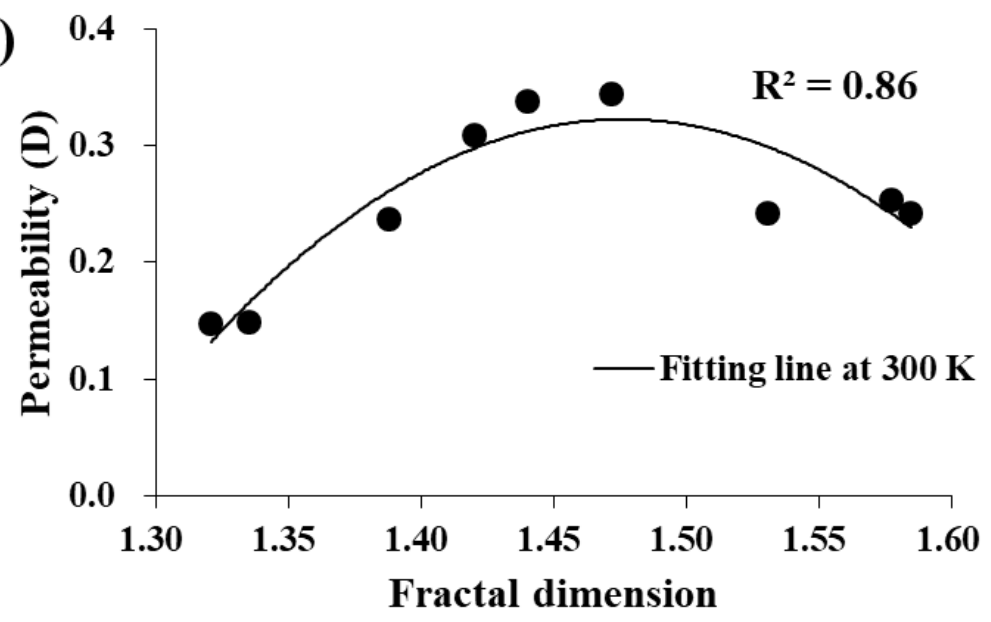

(b)

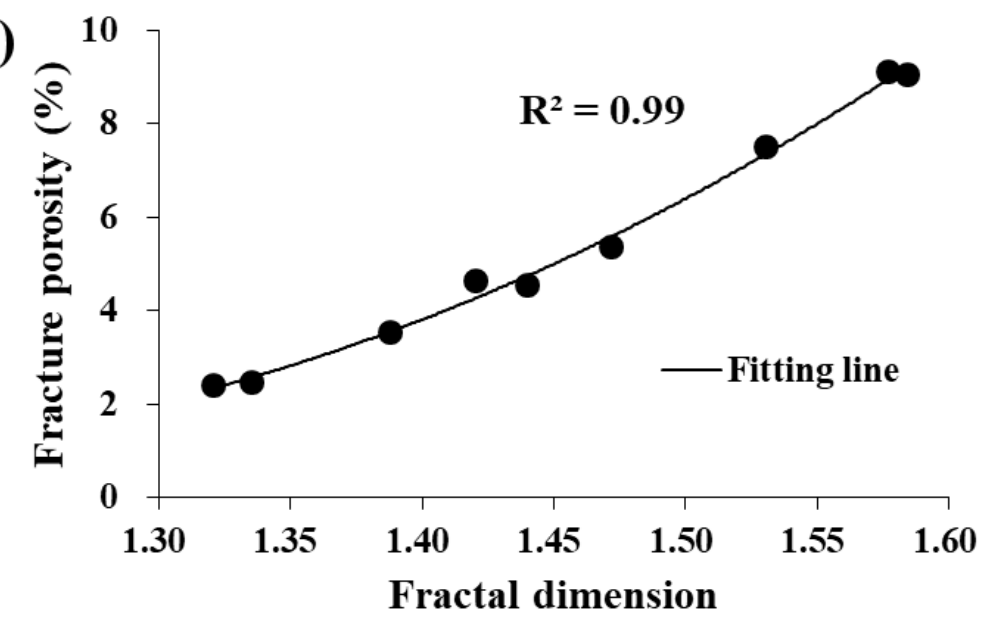

542 Fig. 8. Relations between permeability, fracture porosity and fractal dimension. (a) fractal

543 dimension versus permeability and (b) fractal dimension versus fracture porosity. $\mathrm{T}=300 \mathrm{~K}$, outlet

544 pressure $=10 \mathrm{MPa}$ and pressure gradient $=0.1 \mathrm{MPa} / \mathrm{m}$. 


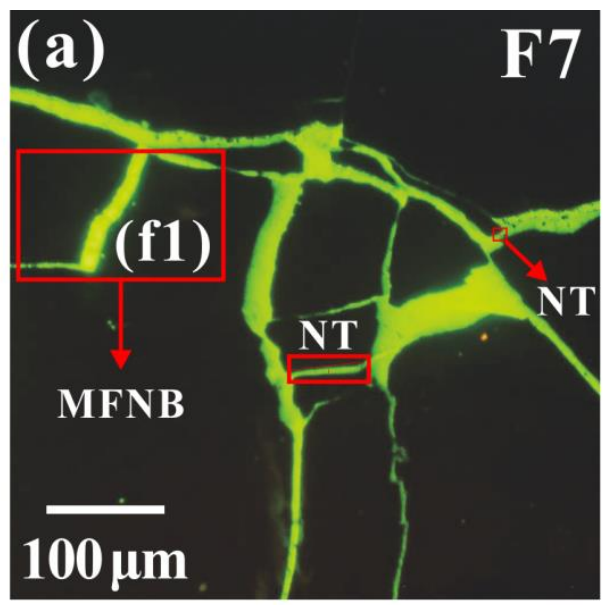

NT: Narrow throats

MFNB: Micro-fracture

network branch
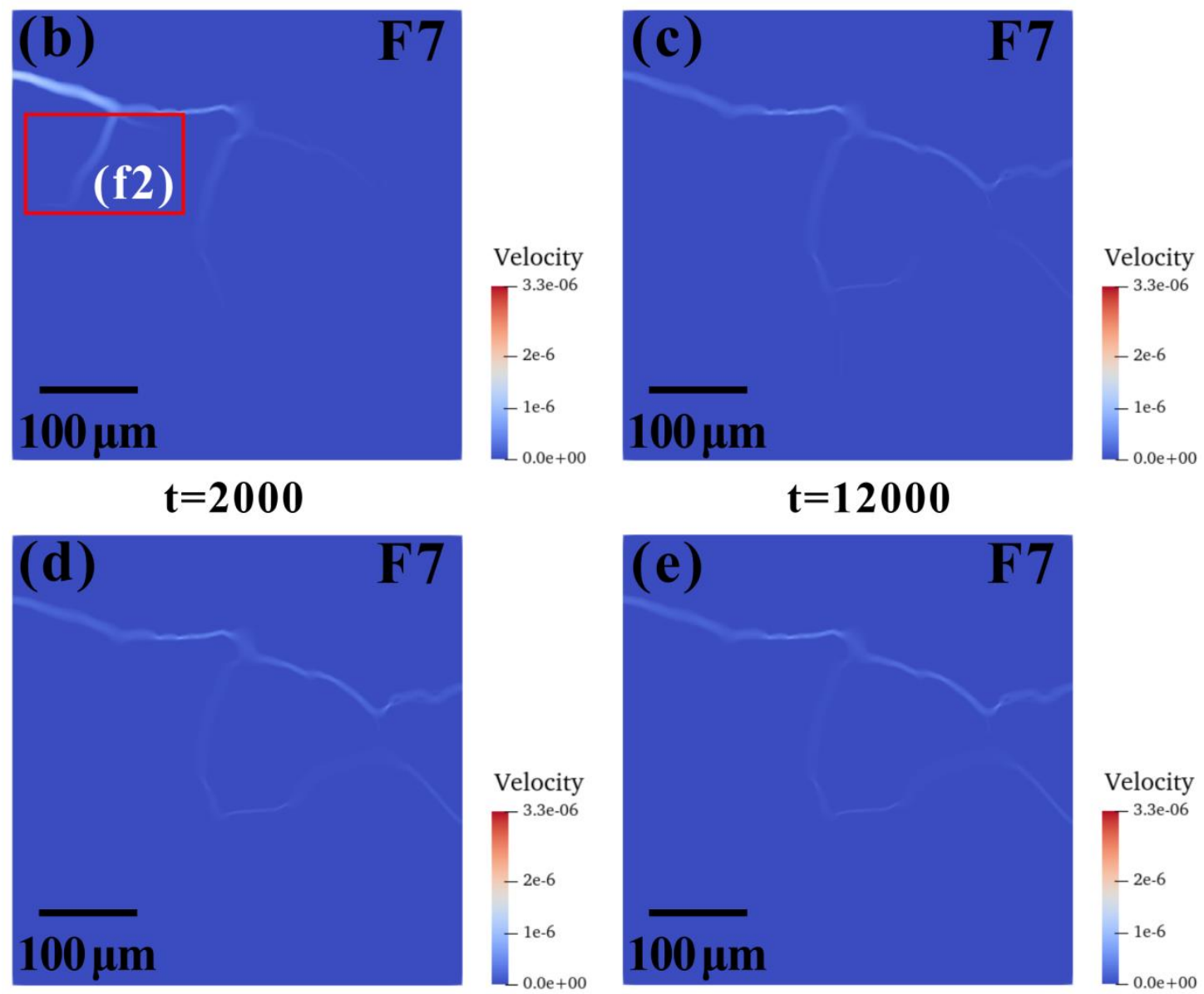
$\mathbf{t}=\mathbf{5 0 1 6 8}$

Fig. 9. Velocity distribution of sample F7 under different time steps. $t$ is the time step. (a) is the initial image of F7 and (b)-(e) are the velocity distribution under different time steps during simulation. $\mathrm{f} 1$ and $\mathrm{f} 2$ are the original image of the branch and the changes that occurred in the branch during the flow process, respectively. 


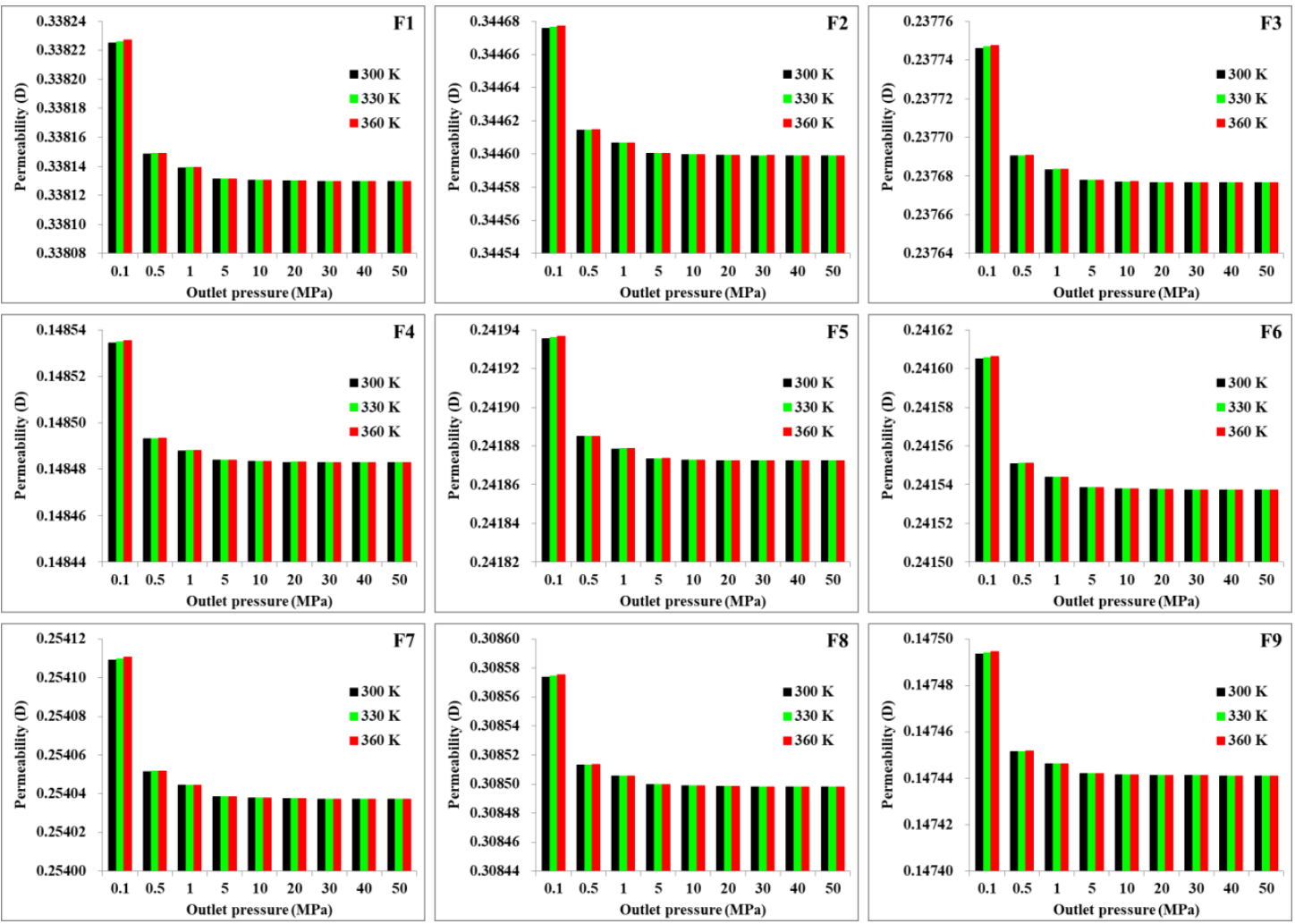

553 Fig. 10. Relations between pressure, temperature and permeability in different samples. Pressure gradient $=0.1 \mathrm{MPa} / \mathrm{m}$. 

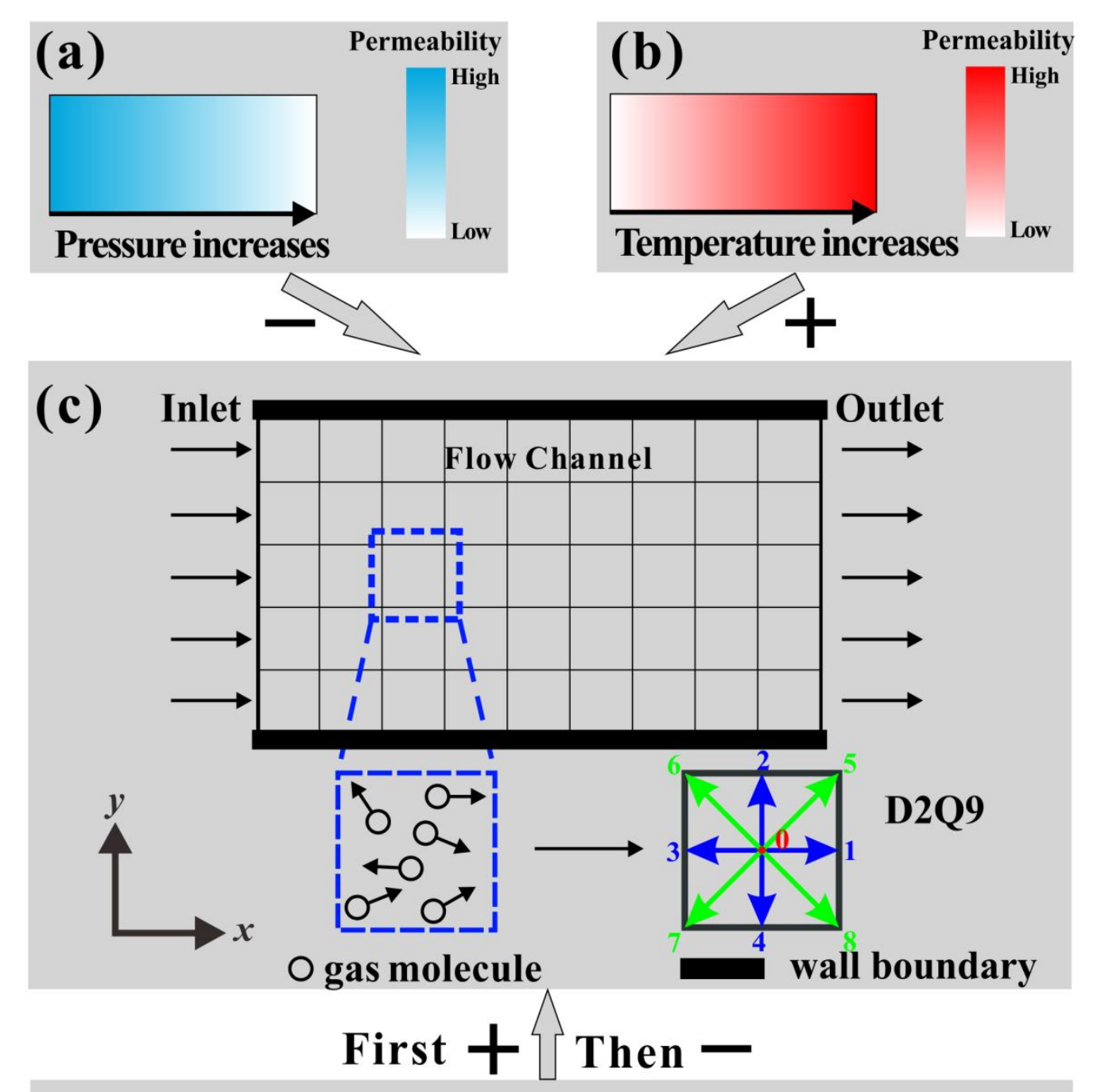

(d) Spatial distribution: Simple $\longrightarrow$ Complex

Fig. 11 Diagram of the influence mechanism of different factors on permeability, including the micro-fracture morphology, pressure and temperature. The positive and negative signs ("+" and "“-") in the figure represent the promotion and inhibition effects, respectively. 
561 Table 1 Sample information and basic parameters of the selected coals

\begin{tabular}{|c|c|c|c|c|c|c|c|}
\hline \multirow{2}{*}{$\begin{array}{c}\text { Sample } \\
\text { no. }\end{array}$} & \multirow{2}{*}{ Basin } & \multirow{2}{*}{$\begin{array}{c}\mathrm{R}_{\mathrm{o}, \max } \\
(\%)\end{array}$} & \multicolumn{4}{|c|}{ Maceral and mineral (\%) } & \multirow{2}{*}{$\begin{array}{l}\text { Fracture porosity } \\
\qquad(\%)\end{array}$} \\
\hline & & & Vitrinite & Inertinite & Exinite & Mineral & \\
\hline $\mathrm{F} 1$ & & 0.62 & 65.4 & 21 & 5.3 & 8.3 & 4.53 \\
\hline $\mathrm{F} 2$ & & 0.65 & 66.2 & 24.9 & 1.4 & 7.5 & 5.35 \\
\hline F3 & & 0.68 & 90.1 & 4.5 & 4.4 & 1 & 3.54 \\
\hline F4 & & 0.89 & 66.9 & 25.6 & 5.9 & 1.6 & 2.45 \\
\hline F5 & Ordos & 1.27 & 90.2 & 8.3 & 0 & 1.5 & 9.05 \\
\hline F6 & & 1.27 & 82.3 & 14.7 & 0 & 3 & 7.50 \\
\hline F7 & & 1.36 & 82.2 & 15.2 & 2.4 & 0.2 & 9.11 \\
\hline F8 & & 1.58 & 84.0 & 11.6 & 0.6 & 3.8 & 4.64 \\
\hline F9 & & 1.78 & 84.4 & 7.9 & 3.1 & 4.6 & 2.41 \\
\hline
\end{tabular}

562

563

564

565

566

567

568

569

570

571

572

573

574

575

576

577 
578 Table 2 Statistics of the length and width for the dominant channel of micro-fractures in Fig. 1.

\begin{tabular}{c|cccc|c}
\hline Figure ID & Fig 1(a) & Fig 1(b) & Fig 1(c) & Fig 1(h) & Average \\
\hline Length $(\mu \mathrm{m})$ & 506.66 & 495.61 & 493.68 & 497.10 & 498.26 \\
Width $(\mu \mathrm{m})$ & 13.63 & 10.19 & 11.13 & 8.88 & 10.96 \\
\hline
\end{tabular}

579

580

581 


\section{Nomenclatures}

$583 \quad r$ : length of boxes

$584 \quad D$ : fractal dimension

$585 N(r)$ : the number of boxes required to completely cover the image

586 FP: fracture porosity

$587 f$ : distribution function

$588 x$ : position of the particles

$589 t$ : time

$590 \quad \delta_{x}$ : lattice size

$591 \delta_{t}:$ time step

$592 \tau$ : relaxation time

$593 \boldsymbol{e}_{i}$ : the discrete propagation velocity vector in $i$ direction

$594 f_{i}^{(e q)}$ : the equilibrium distribution function

$595 \rho:$ density

$596 \boldsymbol{u}$ : fluid velocity

$597 v$ : kinematic viscosity

598 n: spatial dimension

599 b: number of discrete velocity vectors

$600 \quad c_{s}$ : sound speed

$601 \quad c$ : lattice velocity

$602 \quad R$ : gas constant

$603 \quad T$ : temperature

$604 \omega_{i}$ : weight coefficient

$605 K$ : intrinsic permeability with physical unit

$606 K_{L B M}$ : permeability simulated by LBM

$607 \quad L$ : the real scale of coal sample

$608 L_{L B M}$ : the scale of LBM

$609 U$ : normalized streamwise velocity 
Click here to access/download RDM Data Profile XML JFUE-D-20-04146_DataProfile.xml 


\section{Declaration of interests}

$\bigotimes$ The authors declare that they have no known competing financial interests or personal relationships that could have appeared to influence the work reported in this paper.

$\square$ The authors declare the following financial interests/personal relationships which may be considered as potential competing interests:

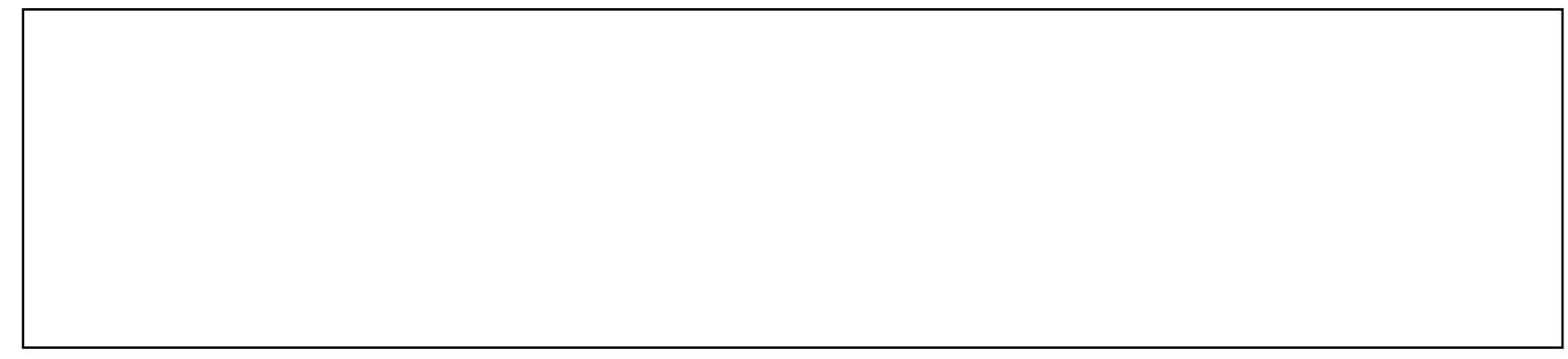




\section{Credit author statement}

Qian Li: Writing-original draft, Investigation, Validation.

Dameng Liu: Conceptualization, Methodology.

Yidong Cai: Conceptualization, Funding acquisition, Supervision, Writing-review \& editing. Bo Zhao: Validation.

Yuejian Lu: Writing-review \& editing.

Yingfang Zhou: Writing-review \& editing. 